\title{
Los bancos comerciales internacionales y las crisis de deuda externa en América Latina: una perspectiva histórica a la luz de la crisis de los ochenta
}

María Werlau

\begin{abstract}
Este trabajo, dividido en tres capituloss, ofrece primeramente un relato histórico y un análisis detallado de la gestación, el desarrollo y el desenlace de la crisis del endeudamiento latinoamericano de los años ochenta. La segunda parte, brinda una perspectiva histórica fundamentada en los precedentes legales y el derecho internacional, así como un recuento de diversos casos históricos de incumplimientos y repudios de obligaciones financieras internacionales. Más adelante, se analizan los elementos del sistema financiero internacional y del comportamiento y la estructura de la banca comercial internacional que explican la tendencia a la crisis del endeudamiento externo, con particular énfasis en la ocurrida en los ochenta. Finalmente, se señalan recomendaciones para fortalecer el sistema financiero internacional en varios niveles para evitar crisis de magnitud en el futuro.
\end{abstract}

\section{Introducción.}

Durante la década del setenta los bancos acreedores de occidente, liderados por los bancos estadounidenses, volcaron sus recursos financieros sobre el mundo en desarrollo, primordialmente sobre la región latinoamericana. A comienzos de los años ochenta el resultante y excesivo endeudamiento externo hizo crisis. Esto tuvo consecuencias inmediatas nefastas para los países latinoamericanos $y$, finalmente, para los accionistas y los gobiernos de los bancos acreedores. 
Al analizar la crisis se hace evidente que la banca acreedora antepuso el deseo de lucro por sobre una seria ponderación de los riesgos implícitos en sus negocios extraterritoriales. Su comportamiento demostró que se supeditaron factores ajenos al análisis crediticio a una seria evaluación de la efectiva capacidad de repago de sus deudores. Por su parte, los países deudores pasaron por alto la importancia de diseñar y aplicar estrategias de financiamiento externo y desarrollo bien ponderadas, $y_{\text {. }}$ razonables. En su lugar, se avocaron a participar activamente de un frenesí crediticio sin precedentes, sustentándose en políticas económicas negligentes y peligrosas.

El trabajo que sigue a continuación es un resumen de una teșis de magister. Su objetivo fue analizar el comportamiento de la banca y demostrar que, aparte de poderosos factores circunstanciales, su desempeño respondió en buena medida a dos elementos que pueden identificarse en las diversas crisis de deuda extema que ha vivido América Latina. ${ }^{1}$

Primeramente, una perspectiva de corto plazo que es característica de la industria financiera y se sugiere como intrínseca al mismo negocio de intermediación de capitales, incluyendo él negocio de prestar. En segundo lugar, imperfecciones del sistêmấ financiero internacional.

En el resumen que sigue se ha eliminado la mayor parte de las cifras y los datos que fundamentan el estudio, para darle énfasis a las conclusiones del trabajo. Esto se ha hecho con la intención de llevar un tema técnico al alcance de un mayor número de lectores.

\section{I.- La crisis de los ochenta: la más reciente crisis de endeudamiento externo en América Latina.}

\section{1.- El financiamiento externo de América Latina después de la Segunda Guerra Mundial: antesala para una crisis.}

Es útil poner en su contexto al auge prestatario que culminó en la crisis de deuda externa de los años ochenta. Si estudiamos los flujos de capitál

\footnotetext{
${ }^{1} \mathrm{La}$ autora incorpora al anälisis sus experiencias personales como ejecutiva del Chase Manhattan Bank, N.A. entre los años 1981 y 1985. Después de completar un curso de un af̃o sobre evaluación crediticia y análisis financiero, pasó a-desempeñarse como ejecutiva para clientes corporativos e instituciones financieras. En San Juan, Puerto Rico, manejó una cartera de préstamos de alrededor de 125 millones de dólares y luego en Caracas, Venezuela, a comienzos de la crisis de deuda externa, ejerció responsabilidad directa sobre una cartera de préstamos de empresas nacionales y multinacionales del sector privado sometida al programa de refinanciamiento de deudas del gobierno venezolano.
} 
hacia la región latinoamericana a partir de la Segunda Guerra Mundial y el comportamiento de los flujos de financiamiento externo, vemos que, por un lado, el auge de la posguerra hizo que las economías tanto industrializadas como de las naciones emergentes crecieran a ritmos acelerados, pero las últimas requerían financiamiento externo. Por otro, la región latinoamericana sostuvo un déficit en cuenta corriente que mantuvo hasta la crisis de deuda de los años ochenta y se reinicia en los noventa. ¿Cómo se suplió la necesidad de financiamiento externo de la región?

Hasta fines de los años sesenta los flujos provinieron mayormente de la inversión extranjera y de la ayuda oficial, pero en la década del setenta ocurre la privatización del financiamiento intemacional. Fueron los bancos comerciales privados los que proveyeron la fuente principal de fondos para la región. Ocurre una agresiva expansión de la banca internacional debido a:

1) El auge comercial de la posguerra que provocó la internacionalización de la producción (multinacionalización de las empresas industriales) y la proliferación de empresas multinacionales. Estas ofrecían atractivos negocios a la banca, ya que requerian servicios financieros sofisticados para invertir y reinvertir sus activos en el exterior.

2) El crecimiento acelerado de las economías latinoamericanas durante la posguerra, fundamentado en modelos estatistas, que proveía incentivos poderosos para prestar bajo riesgo soberano. ${ }^{2}$ Este era considerado seguro y las tasas eran atractivas. ${ }^{3}$

3) La falta de reglamentación de los mercados financieros internacionales contribuyó a acentuar la expansión de los centros de ultramar. La extraterritorialidad permite evadir los requisitos relativos al porcentaje de liquidez, reservas obligatorias en el Banco Central, reglamentación del crédito, seguro de depósitos y fijación de tasas para deudores y acreedores.

4) Varios cambios en el ambiente regulatorio de los Estados Unidos que incentivaron los depósitos en ultramar de las utilidades de las corporaciones multinacionales. ${ }^{4}$

\footnotetext{
${ }^{2}$ Término que se utiliza para referirse a préstamos a gobiernos o al sector püblico.

${ }^{3}$ Suhas Ketkar y Stefano Natella, "An introduction to emerging countries fixed-income instruments", Emerging Countries Capital Markets, CS First Boston, mayo, 1993.

"Otra regulación que también tuvo su efecto fue el Interest Equalization Act de 1964, que afectó las acciones extranjeras u obligaciones/deudas adquiridas por compañias o individuos estadounidenses. Asimismo, en 1968, se impusieron controles obligatorios para las exportaciones de capital de compañías multinacionales de los Estados Unidos. Ibid., p. 205.
} 
5) El reciclaje a través de la banca internacional de los tremendos ingresos generados por los países productores/exportadores de petróleo, con las elevadas alzas de precios (1973-74 y 1978-79). Esto impulsó un fenomenal crecimiento en el mercado de euromonedas. ${ }^{5}$

6) Dentro de la industria bancaria, cambios que contribuyeron al desarrollo del crédito al disminuir la vulnerabilidad de los bancos, canalizar recursos superiores a las capacidades individuales de cada entidad, incorporar instituciones más pequeñas y fomentar el aumento de sus utilidades. Estos cambios obraron como fuertes incentivos para el ingreso de un mayor número de acreedores, y consistieron en la creación del crédito "rollover", 6 de refinanciamiento automático, y la organización de sindicatos o consorcios.

7) La condición deficitaria de muchos países de la región propició el alto endeudamiento y puede atribuirse a varios factores:

- El rápido crecimiento de las exportaciones y la acumulación de reservas internacionales de comienzos de la década del setenta mejoró la capacidad de pago de servicios de deuda y creó una imagen de solvencia.

- La creciente disponibilidad de financiamiento externo a tasas presumiblemente inferiores al rendimiento interno marginal sobre el capital menoscabó el valor real de la deuda y fomentó la apertura y liberación de los sistemas comerciales y financieros en América Latina.

- Políticas internas expansivas de la demanda agregada promovieron el crédito interno y externo.

- Erradas políticas cambiarias produjeron la sobrevaloración de las monedas latinoamericanas e incentivaron las importaciones, desincentivando las exportaciones y la industria nacional. Esto agravó la tendencia al déficit estructural.

\footnotetext{
${ }^{5}$ El término euromoneda es inexacto. En los comienzos se referia primordialmente a transacciones en dólares realizadas en Londres. Luego pasó a utilizarse para todas las transacciones realizadas en cualquier moneda fuera de su pais de origen, llevadas a cabo tanto en Londres como en cualquier otro centro financiero (siendo algunos de los más usuales Hong Kong; Panamá y las islas del Caribe Oriental, incluyendo Bahamas-Nassau). Es de notar, sin embargo, que un estudio de 1984 señala que el $90 \%$ de los eurocréditos de los páses en vías de desarrollo estaban denominados en dólares de los Estados Unidos. En: Ricardo Ffrench-Davis, "Estrategias de los países en desarrollo sobre la toma y el otorgamiento de préstamos privados internacionales", Journal of Development Planning, No 14,1984 , p. 151.

"También conocido como crédito "evergreen", que permanecia siempre en los libros y se refinanciaba automáticamente.
} 
- El pobre criterio y/o el afán politiquero de los administradores públicos provocó un mal uso de los créditos, lo que a su vez creó mayor dependencia sobre éstos. Un gran porcentaje de los préstamos pasó a cubrir el déficit en cuenta corriente, ${ }^{7}$ propiciados por un gran aumento en el consumo de suntuarios, la producción y compra de armamentos, la corrupción y una gigartesca fuga de capitales. Otros se utilizaron para financiar proyectos de inversión sobredimensionados, que quedaron sin terminar o están sólo parcialmente en uso: 8

\section{Comienza un auge prestatario.}

Como resultado se desató una gran competencia por organizar y colocar créditos de consorcio en los países en desarrollo, lo que produjo una tendencia a agrandar los volúmenes prestados y reducir considerablemente los márgenes. Esta guerra de precios alentó a los prestatarios a solicitar volúmenes cada vez mayores de créditos de consorcio e indujo a los prestamistas a buscar un círculo de clientes cada vez más amplio. ${ }^{9}$ Pronto se vieron los resultados.

El crecimiento de la banca internacional y del financiamiento de esta procedencia fue espectacular. En un período de aproximadamente diez años, entre 1966 y 1978, los créditos privados netos de los bancos aumentaron más de cincuenta veces. De esta manera, la proporción del financiamiento externo de procedencia privada pasó de un $39,8 \%$ para $1961-65$ a $92,7 \%$ en 1978.10

La deuda bancaria aumentó rápidamente tanto en valores absolutos como en relación a otros tipos de deuda. Entre 1975 y 1983, la deuda externa de América Latina aumentó más de cuatro veces, de 75 mil millones de dólares a 335 mil millones de dólares, significando esto un crecimiento del $26 \%$ a $56 \%$ del Producto Nacional Bruto. ${ }^{11}$

\footnotetext{
${ }^{7}$ El auge en el consumo de productos importados provocó un déficit de cuenta corriente que en 1981 alcanzó un máximo de 1,6 mil millones de dólares para la región.

${ }^{8}$ S. Griffith-Jones y O. Sunkel, La crisis de la deuda y del desarrollo en América Latina: el fin de una ilusión, (Buenos Aires: Grupo Editor Latinoamericano, 1987), p. 93.

9 "El comportamiento de los bancos trasnacionales y la crisis internacional de endeudamiento", Estudios e Informes de la CEPAL, N76, Santiago, 1989, pp. 52-53.

${ }^{10} \mathrm{E}$. White, La cuestión de las inversiones extranjeras y la crisis económica en América Latina, (Buenos Aires: Centro de Estudios de Desarrollo y Relaciones Internacionales (CEDREI), 1986), p.6.

${ }^{11}$ Heliodoro González, "Latin American debt crisis: the bailout of the banks", Inter-American Economic Affairs, Vol. 39, No3, Invierno 1985, p. 58.
} 
El cambio en la composición de la deuda tuvo efectos importantes sobre las condiciones de financiamiento. La inflación internacional provocó un gradual aumento en las tasas nominales de interés así como un acortamiento de los plazos efectivos de los préstamos. ${ }^{12}$ Esto aumentó la presión sobre los deudores para encontrar fuentes de repago o bien refinanciar bajo nuevas condiciones e incrementó el costo del servicio de la deuda.

A mediados de los años setenta; dos factores de índole externa hicieron detonar la bomba de tiempo del excesivo endeudamiento. En primer lugar, hubo una significativa disminución de la demanda por parte de los clientes tradicionales como resultado de la disminución en el ritmo de crecimiento de las economías de los centros al avenir el término del ciclo de expansión de la posguerra. Como consecuencia, el valor de las exportaciones de los productos básicos cayó abruptamente sufriendo los países periféricos un notable deterioro en los términos de intercambio. ${ }^{13}$

En segundo, la inflación internacional provocó un alza gradual en las tasas de interés y, particularmente, a partir de fines de 1981 el alza en las tasas de interés reales en los mercados internacionales provocó una fuerte alza en el costo del servicio de la deuda acumulada. Consecuentemente, las remesas brutas de América Latina por concepto de pagos de intereses subieron a un ritmo espectacular. ${ }^{14}$ Se estima que en 1981-82, el alza en los intereses añadió 40 mil millones de dólares a los costos del servicio de la deuda externa de los países no productores de petróleo. La deuda aumentó con mayor rapidez que las exportaciones, pasando de ser equivalente al $166 \%$ de las exportaciones de bienes y servicio a un $325 \%$ de éstas. ${ }^{15}$

Ante las circunstancias, los préstamos de consorcio sindicados (syndicated loans) comenzaron su retirada y se tornaba más dificil para los deudores obtener refinanciamientos automáticos ("rollovers") de sus préstamos de corto plazo que vencian.

\footnotetext{
${ }^{12}$ La inflación desencadena una expectativa de mayores alzas, por lo que los bancos acortaban los plazos (vencimientos) para poder ajustar incrementalmente las tasas de sus préstamos (mediante refinanciamientos), a tono con el nivel de inflación. La amortización de la deuda bancaria de corto plazo es el porcentaje de la deuda pendiente a fines de un año que deberã repagarse el siguiente.

${ }^{13} \mathrm{La}$ recesión de las economias industrializadas entre el año 1981 y 1982 le costó a los paises deudores alrededor de $\$ 100$ mil millones de dólares, por concepto de menores volúmenes y más bajos precios. William R. Cline, "La deuda internacional: análisis, experiencia y perspectivas", Revista de la Planificación, N¹6, 1985, p. 13.

${ }^{14}$ De alrededor de 6,9 mil millones de dólares en 1977 a más de 39 mil millones de dólares en 1982.

S. Kehtar y S. Natella, "An introduction...", op, cit., p. 4.

${ }^{15}$ H. González, op. cit., p. 58.
} 
Se desata la crisis.

En febrero de 1982 se anunció la devaluación del peso mexicano, viéndose obligados a seguir la misma ruta ese mismo año Bolivia, Ecuador, Chile, Argentina y Uruguay, y, en febrero de 1983, Brasil y Venezuela. En agosto de 1982, México anunciaba su imposibilidad de cumplir con sus obligaciones externas públicas y solicitaba una ayuda inmediata de fondos nuevos ascendentes a 5 mil millones de dólares. A fines de 1982, había 34 países en desarrollo atrasados en el pago de su deuda externa. ${ }^{16}$

\section{2.- Mecanismos de resolución de la crisis de los ochenta: un largo proceso de refinanciamiento y reprogramación.}

Casi inmediatamente después del advenimiento de la crisis en México, se produjo una caida brusca en los créditos y los flujos de capitales en la región latinoamericana.

Los créditos de los bancos trasnacionales a los países en desarrollo cayeron en promedio a la mitad. ${ }^{18}$ Ocurrió un alza violenta en la captación de depósitos de dichos países (fuga de capitales) y la inversión extranjera se detuvo. ${ }^{19}$ Todo esto, combinado con la elevada remesa de servicios financieros, provocó que a partir de 1982 la región latinoamericana transfiriera recursos netos al exterior. ${ }^{20}$

A partir de 1982, la mayoría de los países deudores no pudo cubrir ni sus pagos de intereses ni las amortizaciones originalmente programadas en sus préstamos.

\footnotetext{
${ }^{16}$ Estudios e Informes de la CEPAL, op. cit., p. 54.

${ }^{17}$ Refinanciamiento es una operación nueva, que sustituye a la antigua obligación prestataria e incorpora nuevas condjciones (tasa, plazo, comisiones, etc.). Este arreglo le permite al banco acreedor aumentar el margen del crédito en función de su mayor riesgo. La reprogramación o restructuración, por su parte, no sustituye al préstamo anterior sino que posterga o reprograma los plazos de repago del préstamo original; tanto en la amortización como en el pago de intereses, y puede contemplar reducciones o descuentos de dichos montos.

${ }^{18}$ De 43 mil millones de dólares anualés durante $1978-1982$ a 18 mil millones de dólares durante 1983-1986.

${ }^{19}$ En 1983, ésta se habia reducido en $79 \%$ del nivel de 1981.

${ }^{20}$ Cerca de 50 mil millones para el bienio 1982-83. Rudiger Dornbusch y Stanley Fisher, "EI problema mundial de la deuda: origenes y perspectivas", Revista de la Planificación del Desarrollo, $\mathrm{N}^{\circ} 16,1985$, p. 93.
} 
Esta situación presentaba condiciones para una crisis de endeudamiento externo de mayor envergadura que las registradas previamente en la bistoria. La base del capital de varios grandes bancos, particularmente en los Estados Unidos, estaba en peligro. Una desestabilización efectiva de la banca mundial, que afectaría el corazón mismo del sistema financiero del mundo occidental, hubiera bastado para producir consecuencias devastadoras para el nivel de comercio y producción tanto de las economías deudoras como de las occidentales.

\section{La etapa inicial de manejo de la crisis: los refinanciamien- tos hasta 1985.}

Fruto de esta situación, la banca y los países deudores entraron en un largo y tedioso proceso que ha representado "la mayor reorganización: de la deuda internacional en la historia financiera".21

Durante la primera etapa de la crisis, el objetivo principal de acreedores y deudores era evitar un colapso del sistema bancario internacional. A fines del 1984, el "exposure" de los principales bancos canadienses y británicos a los países en vías de desarrollo representaba respectivamente alrededor de $195 \%$ y $275 \%$ de su capital. ${ }^{22}$ Los bancos estadounidenses también estaban en una posición particularmente frágil. ${ }^{23}$ Cada uno de estos nueve principales bancos tenía prestado más del $100 \%$ de su capital en cuatro países: México, Brasil, Venezuela y Argentina. La situación de las nueve instituciones bancarias más grandes era aún más crítica ya que sus préstamos a la región representaban $180 \%$ de su capital primario. ${ }^{24}$ Dos de los mayores bancos de Estados Unidos tenían en Brasil préstamos equivalentes a tres cuartas partes de su capital. ${ }^{25}$

\footnotetext{
${ }^{21}$ CEPAL-ONU, "La evolución del problema de la deuda externa en América Latina y el Caribe", 30 de marzo de 1988, p. 3.

22 J. Clark, "Debt reduction and market reentry under the Brady Plan", FRBNY Quarterly Review" Invierno 1993-94, p. 39.

${ }^{23}$ Desde antes de la crisis, los agentes regulatorios habian reconocido que los niveles de activos/capital de la banca estadounidense eran insuficientes. Se promulgaron nuevas regulaciones a principios de los ochenta para subir la tasa de capital primario/activos a 5,5\%, incrementándose del $4 \%$ requerido anteriormente.

${ }^{24}$ CEPAL-ONU, "La evolución...", op. cit.

${ }^{25} \mathrm{~W}$. Cline, "The issue is illiquidity, not insolvency", Challenge, Vol. 27, No3, julio-agosto, 1984.

Ver también capítulo I, 3.
} 


\section{¿Falta de liquidez o crisis de solvencia?}

Durante los primeros años de la crisis se desató un importante debate en torno al origen mismo del problema: ¿era ésta una crisis de solvencia o una carencia de liquidez? Varios expertos internacionales concluían que se vivía una escasez de liquide ${ }^{26}{ }^{26}$ Este tipo de análisis, que definía la crisis en torno a una falta de liquidez momentánea, contribuyó a demorar la búsqueda de soluciones de fondo al problema del endeudamiento y se reflejó en los primeros años de refinanciamiento. ${ }^{27}$ Así, los bancos alegaron estar dispuestos a refinanciar el capital, pero no los intereses vencidos y su fin primordial era mantener al día el pago de intereses. ${ }^{28}$ Como la mayoría de los deudores del sector público mantenían al día el pago de sus intereses, los bancos no se veían obligados a reconocer pérdidas por los préstamos a los países menos desarrollados. ${ }^{29}$ Aducían estar ganando tiempo para que una recuperación en los países deudores les permitiera cumplir sus obligaciones normalmente. Preferían mantener una situación indefinida con respecto al repago del capital, manteniendo, según Biggs, "una especie de renta perpetua que teóricamente podría prolongarse hasta el infinito". 30 De esta manera aumentaron sus utilidades sustancialmente.

Los deudores reconocian la amenaza implícita de que el incumplimiento traería fuertes sanciones así como la marginación de dichos mercados. En aras de su interés propio, decidieron cooperar y se abstuvieron de tomar acciones unilaterales. La cooperación se fundamentaba en una racionalidad económica estrecha de que un repudio de la deuda repercutiria directamente sobre sus economias dependientes del comercio internacional.

\footnotetext{
${ }^{26}$ Ver R. Aliber, "A Conceptual Approach to the Analysis of External Debt of Developing Countries", World Bank Staff Working Paper, N421, octubre, 1980, p. 1.

${ }^{27}$ Un problema de solvencia existe cuando la tasa de interés real en el crédito externo marginal excede el incremento en el ingreso nacional que dicho préstamo ha posibilitado o cuando no existe una alternativa posible para que éste pueda servir su deuda. Por otro lado, un problema de liquidez significa que un deudor es incapaz de obtener suficiente divisa externa para cumplir con el servicio de su deuda de acuerdo a lo programado en el contrato prestatario y cuando las medidas de ajuste y los cambios plausibles en el escenario internacional hacen posible que pueda reducir sus déficit en moneda externa a niveles que posibiliten un financiamiento externo.

${ }^{28}$ Como la función principal de la banca es mantener el dinero en circulación mediante el refinanciamiento del capital otorgando nuevos préstamos para este fin, su viabilidad está inherentemente basada en el pago oportuno de los intereses.

${ }^{29}$ Ver capítulo III, 1.-, para una explicación mäs detallada sobre pérdidas.

${ }^{30} \mathrm{G}$. Biggs, "Aspectos legales de la deuda pública latinoamericana: la relación con los bancos comerciales", Revista de la CEPAL, N25, abril, 1985, p. 176.
} 


\section{Las negociaciones.}

Inicialmerte, la solución del problema se basó principalmente en el aporte de los préstamos no voluntarios, ${ }^{31}$ en función de los acuerdos de condicionalidad del Fondo Monetario Internacional. El tratamiento que se dio a la deuda mexicana en 1982, sirvió de ejemplo para los primeros refinanciamientos interinos de la deuda externa de más de 40 paises emergentes durante los siguientes seis años. Variaron las condiciones en cada caso: los márgenes por tasa de interés, las comisiones, los períodos de gracia ${ }^{32}$ y las condiciones de repago, pero el modelo se utilizó sin grandes alteraciones, en relación a una fórmula simple basada en:

- La estricta condicionalidad de los programas aplicados y vigilados por el FMI que extendió derechos especiales de giro que requerían importantes reducciones en los déficit fiscales. 33 34

- La negociación con comités de acreedores (nombrando un número reducido de bancos para representar a todos los acreedores que negociarían con los deudores) en un contexto de caso por caso (país por separado).

- préstamos nuevos, "no voluntarios", por parte de los bancos acreedores, que permitían mantener al día el pago de intereses.

- los gobiemos acreedores se vieron en la necesidad de contribuir a salvar del colapso a los sistemas financieros nacionales e internacionales, aprobando mayores cuotas para el $\mathrm{FM}^{35}$ y otorgando urgentes préstamos de enlace a los deudores más problemáticos para apoyar sus niveles de reservas mientras se desembolsaban los nuevos créditos por parte de la banca. Asimismo, sirvieron de enlace entre acreedores y deudores.

\footnotetext{
${ }^{31}$ El monto de los créditos "no voluntarios" o "no espontáneos," nuevos préstamos concertados con la intervención del FMl, lo determinan los bancos centrales de los países acreedores y, hasta cierto punto, los mismos bancos acreedores. En S. Griffith-Jones, "Leaming to live with crisis", The Banker, septiembre, 1987, p. 23.

${ }^{32}$ Se refieren al periodo en el cual el deudor no tiene que hacer amortizaciones del capital y sólo paga los intereses.

33 Es notable que, gracias a su respuesta ante la urgencia de la crisis, el FMi logró reafirmar su posición en el financiamiento de balanza de pagos luego de la marginalización de la institución que había ocurrido a raíz de la gran expansión bancaria de los años setenta.

${ }^{34}$ De hecho, era una reprogramación disfrazada de los intereses, ya que tenían por objeto cubrir aproximadamente la mitad de los pagos correspondientes de intereses. En: CEPAL-ONU, "La evolución...", op. cit., p. 5.

${ }^{35}$ El Congreso de los Estados Unidos reconoció la necesidad de compatibilizar la disciplina financiera con las necesidades de los países deudores en desarrollo o, en otras palabras, racionalizar el proceso de reprogramación para que proporcione beneficios tanta a deudores como a acreedores. En enero de 1984 aprobó la Ley Pública N998-181, para aumentar la cuota de los Estados Unidos en el Fondo Monetario Internacional y establecer importantes directrices para salvaguardar la viabilidad económica-financiera de los deudores.
} 
Inicialmente, los bancos privados reprogramaron 130 mil millones de dólares en deuda latinoamericana y comprometieron nuevos préstamos por un total de 17 mil millones de dólares. ${ }^{36}$ En esa época; la mayoria de los deudores se mantuvo al día con el servicio de su deuda.

- Parecía que se había superado lo peor de la crisis; ya que se había evitado un colapso del sistema financiero internacional. Además se veía con alivio el efecto de una breve recuperación en los Estados Unidos, que había incrementado las exportaciones de los países deudores, particularmente las de América Latina: Un buen número de países deudores, al enfrentarse a la crisis, había logrado diversificar su economía y aumentar sus exportaciones considerablemente, logrando superávits de consideración. El nivel de ajuste fue impresionante.

\section{¿Por qué no se resolvió el problema?}

Los programas de refinanciamiento y restructuración tomaban en cuenta sóló los vencimientos de préstamos de corto plazo, preferiblemente no superiores a doce meses, ${ }^{37}$ lo que teóricamente forzaba a realizar una nueva negociación una vez que venciera el capital y éste no pudiera ser repagado.

Los acuerdos de refinanciamiento no habían resuelto el problema de cómo propiciar un crecimiento sostenido en los países deudores. Los programas del FMI basados en políticas recesivas provocaron la peor recesión desde los años treinta y el producto interno bruto de la región cayó en más de $3 \%$ en términos reales. ${ }^{38}$ Se había experimentado una caída general de los salarios reales. En Chile, por ejemplo, el salario mínimo real había caído un 30\% entre 1981 y 1984.

Las transferencias de recursos por concepto de la deuda cobraron magnitudes extraordinarias. Los deudores se quejaban de los crecientes costos del ajuste recesivo en sus economías, así como de los altos costos financieros de las reprogramaciones y comenzaron a tomar medidas. ${ }^{39}$

La banca se rehusaba a asumir el costo de la crisis, cobrando altas comisiones ${ }^{40}$ y elevadas tasas de interés por los préstamos refinanciados

\footnotetext{
${ }^{36}$ CEPAL-ONU, "La evolución...", op. cit., p. 7.

${ }^{37}$ En el caso de deudas pủblicas se consideraron plazos mayores.

${ }^{38}$ E. White, La cuestion...., op. cit., p. 7.

${ }^{39}$ A mediados de 1985 el nuevo Presidente del Perú, Alan Garcia, impuso un límite en el nivel de servicio de deuda en proporción a las exportaciones. $Y$, a pesar de que los demás países deudores no le siguieron los pasos a Perú, sí decidieron formar una concertación de once paises que se denominó Consenso Cartagena.

${ }^{40}$ Un promedio de entre 1 y $1,5 \%$ de los montos refinanciados o restructurados. En G. Biggs, "Aspectos legales...", op. cit., p. 177.
} 
de las deudas que ahora consideraban más riesgosos que cuando fueron otorgados originalmente. ${ }^{41}$ De esta manera, los refinanciamientos aumentaron considerablemente las utilidades de los acreedores durante los primeros años de la crisis. Las utilidades netas de los nueve mayores bancos estadounidenses crecieron entre 1980 y 1986; con la excepción del Bank of America que suffió importantes pérdidas en su cartera de préstamos nacionales.

La contracción de exportaciones de las economías industrializadas hacia los países en vías de desarrollo había causado una enorme pérdida acumulativa del empleo en las economías acreedoras.

La negociación con los comités de bancos permitió ignorar las causas estructurales y la solución de largo plazo del problema era obviamente insostenible e irracional para los deudores. ${ }^{42}$

\section{Comienza la búsqueda de soluciones para una crisis de solvencia.}

El supuesto inicial de que el problema de la deuda era producto de una falta de liquidez momentánea se erosionó rápidamente. Los acreedores se vieron forzados a comenzar a hacer algunas concesiones. ${ }^{43}$

Ante el clima de crecientes dificultades, en septiembre de 1985 durante la cumbre económica de Seúl, el gobierno de Estados Unidos tomó la rienda de la situación con su "Programa de Crecimiento Sostenido", conocido como el Plan Baker por haber sido el Secretario del Tesoro de los Estados Unidos su propulsor principal.

El Plan Baker volvía a incorporar la fórmula de mayores cantidades de préstamos para enfrentar el problema de la deuda, pero también ponía énfasis en la expansión de la liberalización del comercio y la inversión y la reforma tributaria en las economías deudoras para mejorar sus perspectivas de crecimiento. ${ }^{44}$ El objetivo central del Plan Baker era mantener los mecanismos de mercado para el manejo de la deuda, pero reforzados con esfuerzos concertados de política.

${ }^{41}$ En teoria y por lo general en la práctica, el precio de un préstamo (tasa de interés) es función de su riesgo. A mayor riesgo, mayor precio.

42 Por otro lado, es posible que esta creencia inicial pudo haber contribuido a facilitar una búsqueda concertada de resoluciones no confrontacionales de la crisis, evitando la histeria que hubiese podido provocando medidas impulsivas. En la práctica esto permitió que se gestara una toma de conciencia gradual pero probablemente más ponderada, particularmente por parte de los acreedores, sus gobiernos y las entidades multilaterales que entraron en el proceso de resolución del problema.

${ }^{43}$ Se observaron préstamos incrementales ("new money loans'), la extensión de los plazos, mayores periodos de gracia para comenzar la amortización de capital, y la reducción del margen de ganancia ("yield spreads") y de las comisiones por reprogramación.

${ }^{44}$ Ibid. 
¿Por qué fracasó el Plan Baker? Aparte de una serie de razenes colaterales, su fracaso se debió a varios motivos fundamentales.

1) Los créditos incrementales no cumplièron con las expectativas creadas y continuába el aumento de la carga de la deuda para los países deudores.

2) Las negociaciones con los deudores habían tomado un tono crecientemente confrontacional. 45

3) En América Latina el costo político del ajuste y la inmensa carga del servicio de la deuda fomentaba un creciente desasosiego popular. ${ }^{46}$

4) Las instituciones que conformaban el sistema multilateral que había respondido a la crisis estaban llegando al límite del alivio que podían prestar. ${ }^{47}$

5) Entre los acreedores comenzaron a verse señales de un quiebre inminente en la concertación inicial y la divergencia de intereses no dejaba de hacerse sentir. ${ }^{48}$ Esto provocó que la organización de préstamos no voluntarios se fuera haciendo cada vez más demorosa, y se redujo drásticamente la afluencia de nuevos créditos a la región.

6) Los créditos voluntarios incorporados en el Plan Baker, se vieron paulatinamente desplazados por una variedad de "opciones de mercado" negociadas en forma voluntaria entre acreedores y deudores: intercambios de deudas ("swaps') 49 y otros. Dichos instrumentos sirvieron para

\footnotetext{
${ }^{45}$ Brasil habia decidido suspender el pago de intereses (febrero de 1987 ), y los dos paises con mayor deuda, Argentina y México, habían requerido en 1987 nuevos préstamos para poder cumplir con el pago de intereses y no cesar los pagos unilateralmente.

${ }^{46}$ Para 1987 las transferencias negativas de América Latina a sus acreedores, por concepto de pago de intereses y amortización, ascendian a aproximadamente $\$ 25$ mil millones anuales; equivalentes al $25 \%$ de sus exporlaciones. En 1986, el Producto Interno Bruto (PIB) de América Latina estaba todavía $8 \%$ por debajo de su nivel de 1981, aproximándose al nivel que tenia en el 1977. La inversión privada había caído $25 \%$, entorpeciendo el crecimiento futuro, y el efecto de la caída en los recursos dedicados al gasto público en la red social era nefasto. En 1987, los principales deudores tenían $60 \%$ más deuda que en el 1981 y el servicio de su deuda en dólares estaba destinado a aumentar en un $50 \%$ si no se restructuraba dicha deuda. Peor aún, las tasas de deuda a PNB y de servicio de deuda a ingresos por exportaciones habian empeorado progresivamente. Los déficit fiscales se financiaban a través de una expansión del crédito por parte de los bancos centrales, un proceso que provocỏ alta inflación. Las tasas de formación de capital no daban señales de recuperación y los inversionistas locales continuaban retirando recursos financieros hacia el exterior.

${ }^{47}$ P. Mistry, "Third World debt: beyond the Baker Plan", The Banker, septiembre, 1987, p. V. A medida que extendian préstamos en paises de alto rịesgo, su capitalización se habia deteriorado sustancialmente y su estabilidad financiera estaba en juego.

${ }^{48}$ Había diferencias en torno al interés de otorgar nuevos créditos y las prácticas contables y el tratamiento de las reservas para pérdidas y los bancos europeos resentian la hegemonía de los estadounidenses que dominaban los comités.

49 Por ejemplo, los "swaps" de deudas de un pais por otro o los "cocktail swaps" (canastas de préstamos diversos intercambiadas por canastas de otros préstamos diversos), cuyo objetivo era maximizar la eficiencia en manejo de diversos riesgos.
} 
ajustar las carteras de los bancos y disminuir entre los deudores el monto de las obligaciones a reprogramar. 50

7) Todavía varios bancos tenían una enorme vulnerabilidad a posibles incumplimientos y las autoridades fiscalizadoras estadounidenses habian aumentado la presión sobre los bancos para el incremento de sus previsiones para pérdidas ocasionadas por los préstamos problemáticos (" $p r o-$ vision for loan losses' '). 51

Todo lo anterior se conjugó para que finalmente los bancos se ajustaran el cinturón y reconocieran la necesidad de aumentar significativamente sus reservas para préstamos. Citibank estuvo a la delantera del establecimiento de gigantescas reservas para pérdidas para cubrirse de potenciales pérdidas por concepto de sus préstamos a paisès emergentes, aumentando en mayo de 1987 sus reservas en 3 mil millones de dólares. Su acción provocó similares decisiones en la mayoría de los bancos estadounidenses, canadienses y europeos, que declararon enormes pérdidas producto del incremento de reservas relativas a los préstamos de países en desarrollo. $^{52}$

Pero eso no resolvió el problema para la región y no supuso que la banca estaba dispuesta a ceder en las negociaciones. A medida que se había fortalecido la aparente capitalización de los bancos, estaban en mejor posición de reconocer pérdidas y se redujo drásticamente su deseo de otorgar préstamos no voluntarios. Los bancos deseaban retirarse o no aumentar su exposure a los países con los problemas más serios.

Sin embargo, el peligro de los incumplimientos masivos no se había disipado. Seguía existiendo el temor a decisiones unilaterales por parte de dos o tres deudores grandes para obtener un alivio de la carga de su deuda. Para los bancos estadounidenses en particular, aun después de los voluminosos incrementos en la previsión para pérdidas de 1987, las

\footnotetext{
${ }^{50}$ Asimismo, fueron utilizados para hacer inversiones de interés para los banqueros en los mercados deudores. Por ejemplo, Citicorp y otros bancos los utilizaron para capitalizar sus sucursales en el exterior, de manera de posicionarse mejor en los mercados locales.

51 En 1983, por ejemplo, se pasó el International Lending Supervision Act, que obligaba a los bancos a crear y mantener reservas especiales en relación con los paises que enfrentaban dificultades. $G$. Hillocat y C. Quenan, "La banca siempre gana: estrategia de los acreedores frente a la deuda externa", Nueva Sociedad, No94, marzo-abril, 1988, p. 132.

5222 de los 30 bancos estadounidenses con activos de más de 20 mil millones de dólares siguieron la pauta de Citibank en el segundo trimestre de 1987, marcando un patrón de reserva en el cual los bancos estadounidenses y británicos reservaron entre el 25 y el $30 \%$ en capital en relación a su cartera de préstamos en 25 a 30 países deudores. De esta manera, asumieron pérdidas en el segundo trimestre que ascendieron a $\$ 10,7$ mil millones de dólares. Ibid.
} 
reservas no cubrian más del $25 \%$ de la cartera promedio de préstamos a América Latina. ${ }^{53}$

A mediados del 1988; la falta de confianza en las soluciones del Plan Baker se reflejó en una caida sustancial en los valores de la deuda en el mercado secundario. ${ }^{54} \mathrm{La}$ conclusión inevitable era que la solución al problema de la deuda tenía que ser una que atacara el problema de fondo y de forma duradera. Continuar aumentando una deuda que no se podía servir planteaba una alternativa sumamente riesgosa. Se hacia imprescindible concebir un sistema que aliviara a los deudores, a la vez que permitiera la absorción gradual de los costos evitando una crisis repentina que desestabilizara el sistema financiero.

Esto se logró esencialmente gracias al Plan Brady, anunciado en marzo de 1989 por el Secretario del Tesoro de los Estados Unidos, James Brady, quien propuso un nuevo enfoque para una solución más de fondo para el problema de la deuda. Su diseño comenzó a derrumbar importantes barreras. La banca, que se había rehusado a descontar el monto de las obligaciones adeudadas, accedió finalmente a hacerlo. La idea fundamental era devolver la solvencia o creditworthiness a los países deudores. Asimismo, incorporó el concepto de cooperación entre acreedores bancarios, deudores y agencias multilaterales, que proveyeron fondos para asistir a las naciones deudoras a restructurar sus deudas, 55

El Plan Brady incorporaba el concepto de un alivio permanente en la deuda, a realizarse mediante reducćrónes "en monto así como con emisiones de deuda basadas en la dinámíca del mercado. Reconoció la heterogeneidad de los acreedores y pípéporciónó a los países deudores paquetes de financiamiento más a tono con sus necesidades mientras que permitía a los acreedores bajar su exposure. Fue capaz de reducir sustancialmente la carga dél servicio de la deuda externa para los países endeudados.

México fue el primer país en lograr un acuerdo de restructuración bajo las premisas del Plan Brady en diciembre de 1989. Al acuerdo de México le siguieron planes para casi todos los países deudores.

\footnotetext{
${ }^{53}$ En mayo de 1989, el exposure de los diez mayores bancos a los mayores deudores - Argentina, Brasil, México y Venezuela - alcanzaba los 38 mil millones de dólares, casi lo mismo a cuando comenzó la crisis en 1982. "Playing it close to the vest", Latin Finance, mayo, 1989, p. 16.

${ }^{54}$ J. Clark, "Debt reduction...", op. cit., p. 39 .

${ }^{55}$ Mediante el Plan Brady comúnmente se le ofrecía a los prestamistas de cada país un menú de opciones para la conversión de deuda, con alternativas como créditos nuevos que serian convertidos a bonos, recompra de deuda a descuento y conversión de deuda a distintos tipos de bonos.
} 


\section{La reinserción de América Latina en los mercados financieros internacionales. ${ }^{56}$}

Aparte de que muchos países han obtenido alivios importantes en su deuda externa como resultado del Plan Brady, la adopción de políticas monetarias de estabilización de las tasas de cambio, el control de la inflación, la desregulación de industrias claves, la privatización de empresas estatales deficitarias, la prudencia fiscal y la eliminación tanto de precios subsidiados como de barreras arancelarias, son todos indicativos de un interés regional por participar competitivamente de la economia mundial. Asimismo, la mayoría de los países de la región ha optado por la senda democrática, un importante sustento de un manejo económico coherente y estable, ${ }^{57}$

En retrospectiva, quizá lo más rescatable de la reciente crisis de deuda fue que muchos de los países de la región, àl'gunos más temprano y otros más tarde, hayan introducido cambios estruturales que han tenido como resultado el fortalecimiento significativo "de sus economías. ${ }^{58}$ Aunque algunos de estos cambios sean más aparentes que otros, resta por verse cuán sostenible serán a futuro.

Concluyendo, gracias a las fórmulas de rescate que gradualmente se fueron desarrollando se evitó el desplome del sistema bancario y del comercio internacional. La cooperación de acreedores, deudores, gobiernos, bancos centrales e instituciones multilaterales, demostró la adaptabilidad del sistema financiero internacional. Sin embargo, esto se logró sólo tras un doloroso y gradual proceso de toma de conciencià, plagado de enormes tropiezos, gran controversiay elevados costos para todos los involucrados.

\section{3.- Análisis de la crisis de los ochenta.}

En los análisis realizados con posterioridad a la crisis, los expertos asignan distinta prioridad a la influencia de las divcrsas variables en la gestación de la crisis. 59

\footnotetext{
${ }^{56}$ Sobre este tema, ver el capitulo sobre Recomendaciones.

${ }^{57}$ Una excepción notable es el caso de Venezuela.

${ }^{58}$ A pesar del alentador vuelco, resta por verse si esto conduciría a un crecimiento progresivo y a una mayor estabilidad de sus estructuras económicas.

${ }^{59}$ Si es importante destacar que cada país conformó un esquema particular y que el efecto de la variables externas desfavorables varió significativamente en las distintas regiones del mundo en desarrollo.
} 
En este trabajo no es posible entrar en una discusión' sobre la compleja interacción de variables que hemos visto anteriormente y el complicado asunto de la causalidad. Existe un nutrido debate en torno a la importancia relativa de ciertos factores exógenos y endógenos; es conveniente tener presente que frecuentemente es imposible asignar una explicación definitiva a un problema complejo:

Sí es relevante destacar aquí que la responsabilidad del excesivo endeudamiento y la falta de visión para evitar una crisis son compartidas tanto por acreedores como deudores. Aparte del afán de prestar por parte de la banca nada obligaba a los deudores a endeudarse, como tampoco a pagar las altas comisiones cobradas al otorgarse los préstamos. Ya vimos en un punto anterior la dinámica que desató el auge prestatario.

Igualmente, es innegable que numerosos bancos estadounidenses se excedieron en sus compromisos financieros, particularmente en América Latina. Al estallar la crisis, las nueve instituciones bancarias más grandes habían hecho préstamos a la región que representaban $180 \%$ de su capital primario. 60

Posteriormente a la crisis, se supo que los bancos habían violado las normas de organismos oficiales de los Estados Unidos que estipulan que el compromiso máximo con cualquier prestatario en general no debe exceder el $10 \%$ del capital del banco. ${ }^{61}$

Los bancos, asimismo, violaron sus propios procedimientos y normas internas. No faltaron las alertas de un sobreendeudamiento en la región. ${ }^{62}$

¿Cómo se explica entonces este descalabro?

1) Se sugiere una debilidad genérica del sistema financiero internacional que explica una predisposición al excesivo endeudamiento, ya que el reciclaje y el sobrereciclaje de petrodólares sólo explica parcialmente el excesivo endeudamiento. ${ }^{63}$

2) Algunos aseveran que los bancos prestaron aun a sabiendas de que asumían riesgos "malos", 64 organizando préstamos de consorcio con

\footnotetext{
${ }^{60}$ CEPAL-ONU, "La evolución...", op. cit..

${ }^{61}$ Según declaración de J,Charles Partee, Junta de Gobernadores del Sistema de la Reserva Federal, ante el subcomité encargado de la supervisión, reglamentación y seguro de las instituciones financieras, dependiente del Comité de Financiamiento Bancario y Asuntos Urbanos, Cảmara de Representantes de los Estados Unidos, 21 de abril de 1983. En: Federal Reserve Bulletin, (69, 5), mayo, 1983.

${ }^{62}$ La negación de la importancia de la crisis se mantavo aun cuando en agosto de 1982 México hizo públicas sus dificultades para cumplir con el servicio de su deuda externa.

${ }^{63}$ De hecho, el crédito bancario neto a los paises en vías de desarrollo durante ese mismo periodo creció en 275 mil millones de dólares, que fue más del doble del flujo de petrodólares. Ibid., p. 109.

${ }^{64}$ Ibid, p. 55 y "Bottomless Debt", The Economist, 11 de diciembre de 1982.
} 
conocimiento de su pobre calidad crediticia, justificados por su alta rentabilidad ${ }^{65}$ El incentivo que prestaba el potencial de realizar elevadas ganancias parece haber tenido un poderoso efecto. La avaricia y el mal manejo son dificiles de descartar. ${ }^{66}$

3) La fuga de capitales proporcionó un incentivo à là banca, yạ que en una gran parte éstos iban a parar a los mismos bancos acreedores en la forma de depósitos.

4) Como una parte considerable de la deuda externa se extendió a gobiemos u organismos oficiales de los países de la región, tal vez los banqueros subestimaron la importancia de los riësgos que estaban asumiendo en base a una seguridad falsà con respecto al riesgo de prestar a gobiemos (riesgo soberäno). Argüían, sin ninguna base histórica, ${ }^{67}$ que los gobiemos soberanos no caen en incumplimientos.

5) Si hubo dentro de la banca una conciencia real de los riesgos crecientes que se estaban asumiendo, éstos fueron crasamente subestimados. Parece factible suponer que los bancos estaban tan envueltos en el frenesí prestatario que no se percataron de que los objetivos originales de sus préstamos habían cambiado sustancialmente como consecuencia de cambios en el sector extemo.

6) Tanto acreedores como deudores participaron de la ilusión de que los préstamos propiciaban una bonanza en los países deudores, lo que, a su vez, debía generar las condiciones de repago.

\section{II.- Lecciones del pasado: precedentes legales e históricos de interés.}

\section{1.- El derecho internacional y otras consideraciones legales.}

Los contratos de los préstamos de eurodólares contenían cláusulas desfavorables para el deudor en el caso de surgir problemas con el cumplimiento de sus obligaciones. Pero, desde el punto de vista de los acreedores, los contratos eran imperfectos por no ofrecer suficientes garantías que les permitieran efectivamente ejercer el cobro en el caso

\footnotetext{
${ }^{65}$ Ibid, p. 57 y 157. Se hace referencia a S.C. Gwyinn, "Adventures in the loan trade", Harpers, septiembre, 1983, p. 24.

${ }^{60}$ En el capitulo III, 1.-, analizamos este tema con mayor detalle.

${ }^{67}$ Favor referirse a la Parte II de este trabajo, sobre precedentes históricos y legales de crisis de deuda, incumplimientos y repudios de deuda.
} 
de incumplimientos, Pọr esta razón es útil hacer un repaso de la temática jurídica.

Los contratos incorporaban una contradicción con respecto a ciertos principios y costumbres del derecho internacional, así como con disposiciones constitucionales y.jurídicas vigentes en la mayoría de los países latinoamericanos. Estas últimas limitan las facultades de reclamo del acreedor en el caso de incumplimientos o repudios de deuda.

1) Se contraponian particularmente con la Doctrina Calvo y la:Doctrina Drago; que constituyen limitaciones al principio de protección diplomática formulado por Vattel en el siglo XVIII:

- La Doctrina Calvo 68 afirma el derecho soberano de los Estados latinoamericanos de someter reclamaciones de extranjeros a su propia jurisdicción, $y$, en todo caso, a obligar a dichos reclamantes a agotar los recursos jurídicos locales antes de invocar la protección de sus respectivos gobiernos.

- La Doctrina Drago ${ }^{69}$ afirma la inmunidad absoluta de los Estados, sosteniendo que el acreedor debía anticipar que, al celebrar un contrato con un Estado, no podía entablar demandas judiciales en su contra sin su consentimiento previo. Lo contrario limitaba su independencia y hasta pondría en peligro la existencia misma del Estado soberano. Esta doctrina caracteriza a los préstamos públicos como actos de soberanía. ${ }^{70}$

2) Un principio reconocido en la legislación de Estados Unidos declara expresamente inaplicable el procedimiento de quiebra de los

\footnotetext{
${ }^{68}$ Enunciada por Carlos Calvo, diplomático argentino destacado en Francia è importante jurista internacional, adoptada primero por México en 1873 y luego, con gran rapidez en casi todos los países de América Latina. Jbid., p. 76.

${ }^{69}$ En 1902, durante la intervención de tres potencias europeas de Venezuela para exigir el pago de préstamos a entidades públicas de ese pais, el gobierno argentino, próspero socio comercial de los paises europeos acreedores, envió una nota diplomática a los Estados Unidos. El objetivo era presionar para que los Estados Unidos invocara la Doctrina Monroe y rechazara la ocupación territorial en el continente americano por parte de los paises europeos. Su contenido dio lugar al principio que hoy se conoce como la Doctrina Drago. A pesar de ser rechazada en su momento, la Doctrina Drago fue eventualmente reconocida como un principio de derecho internacional en 1936 en la Convención Interamericana para el Mantenimiento de la Paz, logrando su máxima expresión en la prohibición de la amenaza o el uso de la fuerza por un Estado contra otro en la Carta de las Naciones Unidas en 1945 y en la Carta de Bogotá (de la Organización de Estados Americanos) en 1948. En G. Biggs, op. cit. Por su parte, la Doctrina Monroe fue enunciada por el Presidente Monroe de los Estados Unidos en 1823 y fundamentaba una política exterior de solidaridad con las emergentes naciones independientes de las Américas, declarando que consideraría cualquier intento por las potencias europeas de extender su dominio como una afrenta a los Estados Unidos. En: H.E. Davis, History of Latin America, (New York: The Ronald Press Company, 1968), pp. 472-474.

${ }^{70}$ G. Biggs, "Aspectos legales...", op. cit., p. 179, cita a E. Brochard, State insolvency and foreign bondholders, (New Haven: Cambridge University Press, 1.951), Vol.I, General Principles.
} 
Estados e impide que se ponga en peligro la solvencia misma del Estado deudor.

Pero la eficaz aplicación de las disposicionés contractuales de los deudores fuera del territorio nacional es cuestionable y subjetiva. A pesar de las limitaciones que existen para la aplicación de procedimientos de quiebra contra los Estados, nada parece indicar que no podrían los acreedores recurrir à "éstos en el caso de los individuos u sociedades comerciales cuyas deudas hayan caído en incumplimiento, fundamèntándose en:

- La doctrina de la inmunidad restringida, ${ }^{71}$ que impósibilitaría la invocación de la inmunidad de jurisdicción. ${ }^{72}$

- El cobro conforme al derecho privado de la generalidad de los países teóricamente obliga a los tribunales a ordenar el embargo y remate para satisfacer la demanda del acreedor. 7374

Sin embargo, la situación se complica porque, a pesar de los esfuerzos históricos que se han hecho por codificar el comportamiento financiero internacional, no existen normas imperativas convencionales aplicables a o que regulen, la responsabilidad financiera internacional de los Estados y que determinen si sus obligaciones con un acreedor privado extranjero están sujetas al derecho público o privado internacionales. ${ }^{75}$

En el plano interno de los propios Estados deudores, el resultado de procesos jurídicos respecto a las obligaciones financieras externas es altamente dudoso y no existen precedentes claros de los tribunales respecto a las obligaciones financieras internacionales.

\footnotetext{
${ }^{71}$ Concede una naturaleza comercial a los préstamos extranjeros, haciendo una distinción para con los actos de gobierno, que gozan de inmunidad de jurisdicción.

${ }^{72}$ Permitiendo a los acreedores ejercer la totalidad de los recursos permitidos por la legislación de esos paises incluyendo el embargo, las retenciones, los secuestros y los remates de bienes.

${ }^{73}$ G. Biggs,.."Aspectos legales...", op. cit., p. 173.

${ }^{74} \mathrm{Y}$ en los Estados Unidos la legislación concede a los bancos el "right of set-off", un derecho de compensación que les permite aplicar los valores liquidos depositados en cuentas corrientes al pago de aquellas obligaciones que sus clientes les adeuden por otros conceptos. Incluso se puede recurrir a los tribunales para invocar el derecho de embargar los bienes del pais deudor, como lo serian sus exportaciones en tránsito, rematándolos para aplicar el producto a sus deudas en mora. Sin embargo, tendrian que existir depósitos y bienes suficientes de cada deudor para que esta práctica tuviera sentido, y las consecuencias para el comercio internacional que esto supondria no dejan de ser profundamente importantes. La autora conoce personalmente del caso de una empresa venezolana cuyos depósitos fueron aplícados a sus deudas por un banco estadounidense.

${ }^{75} \mathrm{La}$ excepción notable parece ser en lo que respecta a las normas y principios que tratan con los repudios de obligaciones financieras internacionales por parte de gobiernos. Gonzalo Biggs, La crisis de la detida Latinoamericana frente a los precedentes históricos, (Buenos Aires: Grupo Editor Latinoamericano, 1987), p. 86 y 167.
} 
En vista de todo lo anterior, las implicaciones de un repudio de deuda o de una simple moratoria son complejas y las contradicciones son evidentes. Aun los expertos conceden que el asunto es muy complicado. De manera que, en el contexto de la crisis de los años ochenta y sus secuelas, tanto acreedores como deudores han comprendido que la vía judicial es riesgosa e incierta y hasta ahora han optando por la vía de la renegociación de las deudas. ${ }^{76}$

¿Cómo puede entenderse entonces la falta de atención a los riesgos jurídico-legales que asumieron los bancos acreedores?

Teóricamente, al evaluar la oportunidad de prestar o invertir, la perspectiva de obtener utilidades debe mitigar cualquier riesgo jurídicopolítico. Es evidente que no se le dio la seriedad debida a estos riesgos. Pero éstos apenas se toman en cuenta dentro de las mismas instituciones financieras, particularmente con respecto a paises donde el acreedor ha tenido presencia histórica, y salvo casos extremos de países muy inestables, donde son escasas las instituciones que prestan.

¿Qué factores parecen haber contribuido a darle esta falsa seguridad a los bancos? En primer lugar, muchos de los grandes bancos llevan a cabo sus consultas legales con los más importantes bufetes de abogados de sus respectivos países. Esto significa que, por lo general, éstos tienen muy poco conocimiento de las leyes y el sistema jurídico imperantes en los países acreedores. Son bufetes especializados en derecho financiero o comercial, con poca experiencia práctica en derecho internacional.

En segundo, los banqueros y sus abogados no comparten la misma perspectiva de un determinado deudor. La decisión de asumir el riesgo de prestar es fundamentalmente una decisión final de negocio que está fuera del ámbito del asesor legal. ${ }^{77}$ Por su parte, los banqueros, al evaluar todos los riesgos relativos al crédito, muchas veces son incapaces de comprender la complejidad del entorno legal y a veces desestiman sus riesgos tanto por ignorancia como por temor, falta de interés $y / 0$ avaricia.

Una vez que la gerencia de un banco acreedor toma la decisión de prestar en determinado pais, por lo general, todas las evaluaciones de crédito presuponen que el riesgo jurídico-político ha sido determinado como aceptable por los altos mandos. 78

\footnotetext{
${ }^{76}$ Existen instancias de casos llevados a los tribunales, cuyos resultados son contradictorios y sus implicaciones imposibles de predecir. Para más detalle, ver algunos ejemplos en G. Biggs, "Aspectos legales...", op. cit., pp. 180-184.

${ }^{77}$ Además, el abogado no realiza un análisis de riesgo crediticio ni toma en consideración los intereses financieros que justifican el negocio (préstamo).

${ }^{78}$ En general, sólo eventos muy extremos logran provocar una reconsideración de la clasificación de riesgo de un pais.
} 
Igualmente, existe una lógica generälizada de que los riesgos de indole legal/político son intrínsecos a tỏda transacción financiera transnacional. En otras palabras, se acepta que es inevitable asumir estos riesgos parahacer negocios extraterritorialmente. El problema parece ser que existe una tendencia, dada esta presunción, de minimizar dichos riesgos.

Por último, la experiencia práctica parece demostrar que la razón fundamental por la cual los : Estados cumplen con : sus obligaciones financieras no proviene de una norma juridica imperativa, sino máș bien. de su intención de tener la posibilidad de nuevamente endeudarse en el futuro. ${ }^{79}$ Es posible que los acreedores se sintieran confiados con la certeza de que los países deudores perderian más de lo que podrían "ganar" si no pagaban y que el reconocimiento de esto evitaría que recurrieran a no pagar sus obligaciones.

Como conclusión, es importante recordar que el ámbito jurídico no goza de una credibilidad histórica sólida para resolver los conflictos financieros entre los Estados y que muy diversas consideraciones cobran importancia al surgir la necesidad de equilibrar los intereses divergèntes en tiempos de crisis o problemas.

\section{2.- Crisis financieras, incumplimientos y repudios de obligaciones financieras internacionales.}

Desde su nacimiento como naciones independientes, los países deudores latinoamericanos han confrontado problemas cíclicos de envergadura en el pago de sus compromisos financieros internacionales. El análisis de las diversas crisis financieras de interés e instancias de incumplimientos y repudios tomadas de los últimos doscientos años sirve como antecedente para evaluar los factores que han incidido en el pago y el cobro efectivo de las obligaciones financieras externas.

Con respecto a las crisis de endeudamiento externo, se han estudiado las guerras de independencia y la primera crisis de endeudamiento externo en Hispanoamérica (1825); la crisis Baring en Inglaterra y su impacto en América Latina (1890); la intervención de las potencias europeas para efectuar el cobro de las obligaciones de Venezuela (1902); la gran crisis financiera de los años treinta $y$ sus repercusiones en América Latina.

En cuanto a los repudios de deuda externa, los estudios corresponden. a los de los estados del sur de los Estados Unidos (1842, 1866 y 1873);

${ }^{79}$ En Gonzalo Biggs, “Aspectos legales...”, op. cit., p. 167. 
los de la deuda mexicana y otra intervención de las potencias europeas (1861); el de la deuda imperial rusas (1917); y, la Revolución Cubana (1959).

A partir de estos estudios se pueden sacar las siguientes conclusiones:

1) Históricamente se observa que no existe un impacto simétrico en los países deudores y acreedores ante una crisis de deuda o un repudio de obligaciones financieras. ${ }^{80} \mathrm{Se}$ pueden identificar varios factores que han influido en la intensidad de la respuesta ante los repudios de deudas que analizamos, por ejemplo: la naturaleza de los intereses mutuos involucrados, los montos confiscados, el grado de interés geopolítico y económico de los Estados, y todos los que se mencionan en las conclusiones que siguen a continuación.

2) La región ha sufrido de una alta vulnerabilidad por estar su sector exportador sujeto a fluctuaciones externas significativas.

3) Un gran porcentaje de los flujos financieros externos históricos hacia la región ha sido excesivo, improductivo y hasta fraudulento. Incluso, muchas veces ha sido imposible demostrar en qué se han gastado los fondos. 81

4) La interdependencia entre la condición económica de los deudores y su capacidad de pago es innegable.

5) Existe un límite al volumen de los recursos financieros que un país puede transferir al exterior sin que ello trastorne de manera irreparable las condiciones de vida de su población y organización social y política. Es inútil el esfuerzo de pretender cobrar a deudores que no poseen una capacidad de repago adecuada sin antes efectuar los reajustes que permitan fortalecer dicha capacidad.

6) Las medidas coercitivas que buscan extraer el pago de la deuda pública sólo agravan las relaciones entre los Estados y casi siempre no satisfacen los objetivos buscados.

7) No tiene objeto buscar ni sancionar a los culpables. Eventualmente resulta preferible reconocer que todos deben compartir las consecuencias y hacer esfuerzos comunes por resolver la crisis.

8) Los intereses políticos y económicos de los Estados resultan prácticamente inseparables. Los intereses políticos a menudo supeditan

\footnotetext{
${ }^{80}$ D. Félix, "Alternative outcomes of the Latin American debt crisis: lessons from the past", Latin American Research Review, Vol. XXII, N"2, 1987, p. 12.

81 Ibid, tomado de Willy Feuerlein y Elizabeth Hannan, Dollars in Latin America, (New York: Council of Foreign Relations, 1941), p. 17.
} 
la supuesta santidad de las obligaciones contractuales y a menudo se utiliza un pretexto económico con un objetivo esencialmente político. 82

9) En función de lo anterior, las realidades prácticas por lo general finalmente se imponen. Así, los deudores generalmente evitan los atrasos o suspensión en el pago de intereses particularmente a comienzos de una crisis, hasta que la situación se vuelve insostenible. Más importante aún, ningún país latinoamericano ha declarado un repudio de su deuda, incluyendo los más afectados, a pesar del elevado costo social en países que de por sí tienen altos niveles de pobreza. Esta respuesta ha sido el resultado de un cálculo de que el costo de un incumplimiento sería mayor que el costo de servicio de deuda. ${ }^{83}$ Por otro lado, la tumultuosidad del contexto político, como situaciones de guerra y revolución intema, tiende a recibir un tratamiento más favorable por parte de los acreedores.

10) El poder relativo del deudor o grupo de deudores así como del acreedor o inversionista responde, a su vez, a distintos factores de orden político y económico. Durante el desarrollo de una crisis se ven importantes cambios en la relación de poder entre deudores y acreedores. En la crisis del ochenta la magnitud y la persistencia de las transferencias netas negativas de recursos financieros por parte de los deudores y el alto costo socioeconómico, provocó un gran impacto en la relación de poder entre deudores y acreedores. ${ }^{84}$ La capacidad tanto de los acreedores como de los deudores de reaccionar en bloque ha sido importante para determinar su efectividad y traspasarse la mayor carga de uno a otro. Los

\footnotetext{
${ }^{82}$ G. Biggs, funcionario del Banco Interamericano de Desarrollo y respetado autor de varios libros y artículos sobre la deuda extema señala que, llegado el momento, el interés nacional es el que prima, de manera que: "...en la medida en que el gravamen de la deuda también afecta de manera critica el ejercicio de las funciones básicas del Estado, sus efectos trascienden los limites de una relación puramente contractual, civil o comercial y adquieren una evidente connotación pública". G. Biggs, "Aspectos legales...", op. cit., p. 162.

83 Aparte de la incertidumbre en torno a las posibles consecuencias de un incumplimiento, el formar un cartel de deudores para rechazar las obligaciones financieras operaba contra el interés de los paises individuales de mejorar su propio "credit rating" para participar de futuras oportunidades. Referirse al capitulo II sobre posibles consecuencias legales y al capitulo III, sobre el comportamiento de los deudores.

${ }^{84} \mathrm{Al}$ respecto una autora sostiene: "Cuando las transferencias netas de recursos financieros se dirigen hacia un pais en vias de desarrollo, la mayor fuerza negociadora es de los prestamistas, ya que son éstos quienes toman la decisión final frente al otorgamiento de nuevos fondos y su transferencia. Esto implica que el prestamista puede imponer todo tipo de condiciones con suma facilidad. Cuando las transferencias netas son negativas, esa fuerza negociadora realiza un viraje potencial hacia el gobiemo deudor, puesto que éste podria decidir no pagar, primero, y después no efectuar la transferencia de fondos. En consecuencia el deudor está, en este caso, no sólo en una posición que le permite resistir las condiciones del prestamista sino, sobre todo, imponer sus propias condiciones...". S. Griffith-Jones, " 2 De quién es la crisis de la deuda?", Cuadernos del CLAEH, $\mathrm{N}^{\circ} 43$, Año $12,2^{2}$ serie, $1987-3$, p. 42.
} 
acreedores, o sus países, a menudo deben supeditar el interés nacional a sus legítimos reclamos financieros, morosos o repudiados. 85

11) El "laissez faire " ha carecido de una respuesta histórica satisfactoria y al percibirse una crisis como un asunto de interés nacional, los organismos oficiales y multilaterales terminan desempeñando un rol primordial en la resolución del conflicto gracias a la prudente intervención de los gobiernos y organismos multilaterales.

12) Aunque América Latina tenga un poder militar y político relativamente menor en el plano global, sí representa un mercado de consideración para los países industrializados. Asimismo, la histórica búsqueda de la estabilidad socio-política de la región ha tenido gran importancia en el manejo geoestratégico de la política exterior de los Estados Unidos.

13) Los inversionistas y acreedores, supuestos actores sofisticados del ámbito financiero internacional, son a menudo poco "racionales" y hasta concientemente negligentes en la toma de decisiones financieras. Las crisis financieras estudiadas dan sobrada muestra de esto. ${ }^{86}$

14) Existe poca memoria colectiva en los mercados financieros internacionales. Las lecciones legadas por la historia, aun en el sofisticado mundo de las altas finanzas, tienden a olvidarse muy pronto.

\section{III.- El comportamiento de la banca comercial internacional y el sistema financiero internacional.}

\section{1.- El crédito bancario y el sistema financiero internacional.}

Al analizar la crisis de la deuda de los ochenta, es notable comprobar que los bancos acreedores hayan fallado tan rotundamente en su evaluación de riesgos. En definitiva, reconocían que, de suscitarse incumplimientos,

\footnotetext{
${ }^{85}$ Por ejempio, durante la Segunda Guerra Mundial, por la necesidad de enfrentar la amenaza nazi, la Unión Soviética pasó al campo aliado contra Alemania, recibiendo elevadas sumas en ayuda militar y humanitaria, así como préstamos para sufragar la guerra. Por otro lado, en el caso de Cuba, que no es ni una potencia política ni económica, los Estados Unidos se ha dado el lujo de aislar al régimen política y económicamente porque en balance sus intereses nacionales se lo han permitido. ${ }^{86}$ Por ejemplo, sobre la crisis del treinta en un testimonio del Congreso de los Estados Unidos se dijo: "... el historial de las actividades de los banqueros de inversiones ("investment bankers') al ofrecer emisiones extranjeras es uno de los capítulos más escandalosos de la banca americana. La venta de estas obligaciones se caracterizó por prácticas y abusos que violaron los más elementales principios de ética en los negocios. Los adjetivos utilizados parecen apropiados para describir el frenesí prestatario de los años setenta". H. González, op. cit., p. 56, tomado de Stock Exchange Practices, Report on the Committee on Banking and Currency, U.S. Senate, Report 1455. Traducción nuestra.
} 
ellos mismos sufrirían las pérdidas. Pero las instituciones acreedoras pasaron por alto elementales fundamentos teóricos de la evaluación crediticia, pilar mismo de su actividad prestataria. Es útil analizar algunas características del negocio bancario que pueden ayudar a explicar su comportamiento.

\section{Los fundamentos teóricos del análisis crediticio y la banca: la lógica del crédito.}

La lógica crediticia no sólo posibilita la supervivencia misma de la entidad acreedora, sino que también hace posible que la actividad de prestar se realice en función del objetivo central de su negocio, que es el de devengar utilidad. Esta lógica, fundamento teórico del crédito, tanto nacional como internacional, se sostiene sobre la base de que el deudor debe poseer una capacidad de repago y se encuentra plasmada en los requisitos internos, contables y legales que rigen a las instituciones financieras. Dicha capacidad de repago depende de una determinación de que un deudor es sujeto digno de crédito y es función de la constatación de que los préstamos son otorgados conforme a condiciones financieras del deudor que sean propicias para su endeudamiento; el uso productivo del crédito, lo que posibilitará la generación de los medios de repago; la viabilidad y solvencia del deudor, que en parte se mide en función de riesgo, e incorpora una evaluación del contexto macroeconómico y político en el cual éste opera.

Es posible examinar en detalle el aspecto técnico delineando los requisitos internos de las instituciones bancarias, así como los que son impuestos por las autoridades de cada país y las deficiencias en el análisis de crediticio, temas en los cuales no podemos entrar aquí. Lo que sí es necesario destacar es que la evaluación de riesgos globales ha estado rodeada de deficiencias históricas que han contribuido a las dificultades de un ejercicio de por sí subjetivo y complejo.

El negocio bancario parece permitir amplia rienda a una "falla humana" que hace que no nos guste ver lo que no se quiere ver, y a menudo nos hace permanecer inmunes a lo negativo si nos trae perjuicio. Esta no es una característica exclusiva de la banca, 87 pero sí es notable en el negocio bancario por fundamentarse éste en el cálculo acertado para la toma de riesgo. 88

\footnotetext{
${ }^{87}$ Bien sabemos que los deudores manifestaron la misma tendencia al hacer caso omiso a las señales de peligro, dejando a un lado el cuidadoso examen de sus propias capacidades y limitaciones ante la tentación de tomar prestado fácilmente.

${ }^{88}$ Teóricamente, a mayor riesgo, mayor precio/utilidad.
} 
Se observa una tendencia en la industria prestataria de caer presa del "entusiasmo inmediatista" a pasar por alto importantes consideraciones relativas al riesgo y a la capacidad de repago de los deudores en el plano internacionali, La banca ha carecido de visión histórica y profunda de la naturaleza de sus deudores y de los mercados donde ha operado por no poseer un conocimiento profundo del país deudor; existir una tendencia de dejar primar una "microvisión" del deudor (empresa pública o privada), en una especie de perspectiva no inntegrada a șu medio, obviándose factores esenciales relativos a la economía deudora, como lo son el riesgo jurídico-político o macroeconómico (incluyendo el relativo a política-cambiaria); existir una tendencia marcada a enfocar el corto plazo. La visión estratégica y la planificación de trayectorias de mediano y largo plazo tienden a concentrarse en las oportunidades de lucro que vayan su'scitándose en el campo amplio de las actividades de negocio.

Algunos factores que ayudan a explicar lo señalado anteriormente son:

1) La mecánica de la competencia impide que el mercado financiero en su conjunto cuestione las políticas económicas de los países deudores. 89

2) El análisis estadístico es inexacto y poco fiable por varias razones. ${ }^{90}$ Es sumamente dificil obtener datos estadísticos exáctos, problema. que tienen incluso los paises desarrollados con mayor avance tecnológi$\mathrm{co}_{3} \mathrm{y}$, adicionalmente, tiende a existir gran demora en la publicaciôit de datos constatados. ${ }^{91}$ Asimismo, los datos estadísticos tienden a estar sujetos a influencias de orden político y en muchos de los países menos desarrollados los bancos centrales no gozan de autonomía del gobierno.

3) No existe un estándar internacional de prácticas y criterios contables, por lo que la información está sujeta a diversas formas de presentación, dando lugar a una suerte de ciencia inexacta.

4) Las entidades regulatorias tienden a establecer criterios de evaluación de los países deudores no siempre basados en análisis autónomos e independientes. En los Estados Unidos, por ejemplo, el Congreso ha

\footnotetext{
${ }^{89} \mathrm{R}$. Devlin, "Banca privada, deuda y capacidad negociadora de la periferia: teoria y práctica", en: A. Bianchi (ed.), La deuda externa latinoamericana, (Buenos Aires: Grupo Editor Latinoamericano S.R.L., 1985), p. 324.

${ }^{90}$ C. Ganoe, "A banker's view: country analysis", Developing country debt, pp. 9497.

${ }^{91}$ Por ejemplo el Fondo Monetario Internacional no publicó cifras de 1971 de balanza de pagos hasta el 1974 por no ser hasta entonces que los paises miembros suplieron los datos necesarios. Posteriormente, el Fondo comenzó a publicar cifras a medidas que se recibierain.
} 
criticado que los reguladores hayan recibido casi toda su información de bancos acreedores, las mismas entidades que debían regular. ${ }^{92}$

5) Muchos análisis de Country Risk obvian factores de índole sociopolítico relacionados con el riesgo soberano, que efectivamente ejercen un impacto tanto en la capacidad como en la voluntad del repago.

6) En general, la industria bancaria no ha asignado debida importancia histórica al análisis macroeconómico.

7) Las proyecciones para determinar capacidad de repago y solvencia tienden a ser deficientes por no tomar en cuenta distintos escenarios macroeconómicos. En el caso de la evaluación de crédito que se hacía para los deudores latinoamericanos hasta el momento de la crisis de los ochenta, las proyecciones generalmente se realizaban en función de un ámbito macroeconómico no cambiante; por ejemplo, no se tomaba en cuenta el efecto de una devaluación de la moneda local.

8) El rol de los economistas dentro de las instituciones bancarias está mal planteado. No visitan con debida frecuencia a los países que analizan, no gozan de participación en las ganancias del banco en la forma de bonos de reconocimiento como lo hacen los ejecutivos de la línea de negocio (los que manejan las relaciones de negocio con los clientes), y sus análisis y predicciones desfavorables tienden a contraponerse con el objetivo de los primeros, que es prestar para generar utilidades, lo que impacta favorablemente en términos de su prestigio y compensación y sus posibilidades de avanzar en su carrera.

9) Se ha observado una tendencia a no destinar al país deudor suficientes funcionarios calificados y de alto nivel que puedan establecer amplios y diversos contactos que mejoren la calidad de sus análisis y hacer que éstos sean fiables. ${ }^{93}$

10) Por razones similares a la anterior, ha existido una falta de personal calificado o con suficiente experiencia para desempeñar la función crediticia internacional cabalmente.

11) En la banca, el ejecutivo que maneja la relación de negocios de la institución con un cliente tiene amplia discreción en relación al manejo de la información y opera en una suerte de vacío con respecto al análisis macroeconómico.

12) Ha existido una contraposición de objetivos inherente a la doble función de los ejecutivos de crédito: crecimiento y utilidades contrapues-

\footnotetext{
${ }^{92}$ Tbid., p. 99.

${ }^{93}$ Este es el caso también en las evaluaciones de otros instrumentos de deuda e inversión que se llevan a cabo en instituciones financieras diversas.
} 
to a la toma cautelosa de riesgos. El interes de los funcionarios que recomiendan y aprueban los negocios de realizar una transacción que devengue lucro tiende a crear una predisposición a confiar en una evaluación crediticia que no haya tomado en cuenta de manera responsable el contexto macroeconómico. ${ }^{94}$ Por esta razón, el análisis de riesgos en sí está "autolimitado."

13) Lo anterior se debe a la naturaleza de la entidad financiera modernay, en general, lo que define ala corporación de hoy como exitosa exige una búsqueda de ingresos incrementales para mantener la competitividad en un mercado financiero cada vèz más complejo. Este sistema de remuneración es inherente al mercado accionario capitalista y, desde ese punto de vista, refleja una debilidad del sistema.

\section{Algunas observaciones sobre el sistema financiero internacional: patrones cíclicos de endeudamiento externo $y$ crisis financieras.}

Un primer punto, es que en casi todas las crisis financieras se presentan tanto factores endógenos como exógenos.

Al mismo tiempo, se han identificado patrones históricos de endeudamiento externo que corresponden a instancias de relativa apertura o cierre del comercio internacional, surgiendo los periodos de crisis (incumplimientos o refinanciamientos) en las fases en que el comercio internacional experimenta un cierre.

Igualmente, se observa una tendencia cíclica en el surgimiento de crisis de deudas así como patrones similares en su gestación y desarrollo. El detonante de las crisis de deuda es producto primordialmente de tendencias endógenas de los mercados financieros capitalistas, cuando carecen de regulación, de llevar al exceso los auges en el prestar. ${ }^{95}$ Esto cobra particular relevancia porque el comportamiento de la banca es

\footnotetext{
${ }^{94}$ En la experiencia personal de la autora en Chase Manhattan Bank, un préstamo nuevo se otorgaba luego de una revisión del comité de crédito de un Senior Officer ApprovalMemoran tum (S.O.A.M.), documento que incorpora un microanálisis del deudor así como del objetivo del préstamo. La consideración de riesgo más global que se hacia era en relación a factores relativos a la industria donde operaba dicho deudor. No se incorporaba un anälisis de factores macroeconómicos o extemos, como los serían el impacto en el estado de situación de un deudor de un alza de intereses o una devaluación de la moneda. El ejecutivo que sometia dicho S.O.A.M. a aprobación lo hacia bajo la presunción de que el banco había ya decidido prestar en ese pais y habia tomado en cuenta los riesgos de hacerlo. Adicionalmente, éste por lo general no poseía la información macreconómica relevante, ya que esa no era su especialidad como tampoco requisito para cumplir con sus responsabilidades. Por lo que se ha podido observar, esta práctica no ha variado significativariente hasta el dia de hoy. ${ }^{95}$ D. Félix, "Alternative outcomes...", op. cit., p. S. Traducción nuestra.
} 
procíclico, o sea, los préstamos fluyen a las economías que se perciben o efectivamente están èn crecimiento o en mejor situación económica. Sin embargo, disminuyen cuando la situación del país se deteriora, por lo que los compromisos que adquiere el deudor de servir sus préstamos no responden a los cambios en su situación económica. Esta característica del endeudamiento es de singular importancia, ya que la deuda debe ser pagada tanto en tiempos buenos como malos y los deudores que toman deudas en moneda extranjera deben obtener la divisa requerida para el servicio de dicha deuda sin importar las fluctuaciones que puedan ocurrir en el sector externo. De esta manera, la respuesta de los acreedores bancarios ante el surgimiento de dificultades es de detener repentinamente los flujos crediticios al surgir las primeras indicaciones de problema, como es un alza en las tasas de interés. Esto, a su vez, tiende a provocar una escalada en las dificultades de repago y, por tanto, mayor deterioro en la capacidad de pago, que tiende a provocar los incumplimientos. El ciclo tiene distintas fases: expansión, auge y escalada de préstamos y creciente acumulación de deuda ("debt buildup'). Los mercados han demostrado ser incapaces de señalar con precisión los límites viables a la escalada de préstamos.

Varios economistas, desde Marx hasta Schumpeter, han demostrado que la banca incluso amplía el ciclo económico por medio de sus prácticas prestatarias. ${ }^{96}$ Así, la banca se convierte incluso en un factor desestabilizador, acentuando el daño de las políticas económicas inadecuadas y sirviendo como elemento catalizador de crisis.

Finalmente, el comportamiento procíclico de la banca es contrario a la intención del sistema monetario internacional concebido en Bretton Woods, que creó agencias multilaterales de crédito como el Fondo Monetario Internacional y el Banco Mundial para añadir un factor anticíclico que prestara estabilidad al mundo frente a las fluctuaciones del mercado liberal.

\section{¿Por qué el crédito bancario exclusivo es incompatible con el desarrollo?}

En función de las limitaciones señaladas, se sostiene que la banca comercial sólo puede tener un rol suplementario en el desarrollo por diversos motivos: 97

\footnotetext{
${ }^{96}$ Schumpeter, por ejemplo, considera a la banca y a las eventuales crisis de crédito como un aspecto dinámico del capitalismo, parte de un proceso de "destrucción creativa".

${ }^{97}$ Tomado en parte de R. Devlin, "Los bancos comerciales y el desarrollo de la periferia: congruencia y conflicto", Revista de ta CEPAL, diciembre, 1979, p. 78.
} 
- Una gran parte de los recursos bancarios proceden de depósitos a la vista o a corto plazo, lo que otorga una orientación cortoplacista a su forma de prestar. Esto impone límites para prestar a largo plazo, ya que la falta de correspondencia entre los vencimientos no puede exceder límites prudentes. Por esta razón la banca privada no puede ser un sustituto adecuado de las agencias financieras internacionales oficiales, ni puede atender el espectro total de las necesidades de financiamiento externo de los países en desarrollo.

- Los banqueros deben mantener una actitud conservadora frente a las perspectivas de amortización de sus préstamos, ya que sus recursos provienen de la garantía que puedan ofrecer a sus depositarios y de la capacidad de evitar las pérdidas en sus carteras de préstamos. Sus criterios de solvencia, por tanto, están sumamente guiados por la medida de liquidez en el servicio de la deuda, lo que explica el interés de la banca en mantener el servicio de la deuda al día, aun a pesar de la típica deflación de la economía deudora para liberar divisas para el servicio y la amortización de su deuda durante los ciclos bajos. ${ }^{98}$

- Pareciera existir una relación inversa entre la demanda y la oferta del crédito bancario de un país en desarrollo. Los bancos compiten con ahínco para prestar en los "países vírgenes" no excesivamente agobiados por deudas extemas y considerados como solventes. A medida que el país se endeuda decrece el interés por prestar, baja que podría ser en parte contrarrestada por la entrada de nuevas instituciones prestatarias. Pero al desaparecer la capacidad de pago por una problema de liquidez o solvencia, desaparece la competencia por prestar y hasta se cierra absolutamente el acceso al crédito, empeorando la situación del deudor. ${ }^{99}$

\section{Recomendaciones.}

\section{La reintroducción de América Latina y las naciones} emergentes a los mercados internacionales de capital.

$\mathrm{El}$ rol del endeudamiento externo en el diseño de los planes de desarrollo y las políticas macroeconómicas merece una seria reconsideración.

A medida que desaparecen a pasos agigantados las fronteras económicas de los Estados y se multiplica el número de protagonistas no

\footnotetext{
${ }^{98}$ Esto también explica por qué es preferible el crédito en forma de emisiones de:bono o préstamos de largo plazo de organismos multilaterales para financiar programas de desarrollo.

${ }^{99}$ Ibid., p. 84.
} 
tradicionales que entran en la escena internacional financiera, la firme tendencia a la globalización de los últimos años impone una reflexión. Se vislumbra el continuado incremento de la internacionalización del comercio y las finanzas, así como la participación de un mayor número de países en la identificación de las ventajas comparativas a nivel mundial. Estas no sólo son determinantes de la asignación de los recursos para el comercio, sino también de los capitales.

América Latina ha vuelto a acceder al capital internacional y se han repatriado elevados capitales fugados. Es el sector privado el medio en el cual se intermedian la mayor parte de los fondos internacionales requeridos para la inversión, la producción y el crecimiento. Pero se ha perfilado una creciente autonomía del capital de procedencia bancaria, en forma de deuda, prefiriéndose sofisticados mecanismos de inversión, lo que ha significado un creciente acceso a la inversión extranjera directa. 100

Este mejor panorama también indica que el endeudamiento externo podría volver a ser una alternativa real en un futuro no muy lejano. Pero aunque el ambiente financiero actual indique que se han superado los peores momentos de la reciente crisis, es preciso no olvidar sus elevados costos. La región tiene todavía un largo camino que andar para pasar de ser clasificada como región en vías de desarrollo a región desarrollada.

Hoy los países de América Latina que compiten en un mundo más abierto también se enfrentan a un mayor número de protagonistas en busca de los mismos capitales, enormes, pero limitados y disponibles mediante mecanismos crecientemente complejos. Se habla incluso de un déficit global de ahorros, aunque no existe prueba empírica al respecto. ${ }^{101}$

Ante esta realidad, los países de América Latina deben continuar sus esfuerzos por superar el subdesarrollo insertando las estrategias de captación y utilización de los capitales extranjeros dentro de un compromiso estratégico con políticas realistas que puedan satisfacer las necesidades de crecimiento y garantizar el uso productivo y responsable de estos capitales.

Con nuestra aproximación histórica, teórica y analítica, se ha pretendido ilustrar las deficiencias del sistema financiero internacional y la

\footnotetext{
100 Ya en 1992, a sólo diez años del inicio de la larga crisis, el Banco Mundial informó una inversión extranjera directa en. América Latina de 12,3 mil millones de dólares. En: AmericaEconomia, Número Especial: Las 500 empresas más grandes de América Latina, 1993-94, p. 21.

${ }^{101}$ Por ejemplo, se señala que la demanda por el capital inversionista es mayor por parte de los paises asiäticos, pero también esto supone que aumentarả el ingreso y los ahorros en estas economías, lo que financiará la subsiguiente demanda local. Las economias asiáticas tienen las más altas tasas de ahorro. Ver R.W. Forsyth, "Just say no", Barrons, 7 de noviembre de 1994, p. 19.
} 
necesidad de dar soluciones estructurales y sistémicas para el manejo del financiamiento internacional. Dichas soluciones deben ser coherentes y pueden ser efectivas a través del tiempo y de las fronteras, y se hacen imperantes con la creciente interacción de los Estados en todos los. planos.

Para terminar, esperamos que hayan quedado claros los siguientes puntos:

- La necesidad de considerar estándares internos más estrictos por parte de los organismos fiscalizadores tanto en los países deudores como en los países acreedores.

- La importancia de una consideración de estrategias deseables de financiamiento externo en el diseño de los planes de desarrollo de los países de la región y la necesidad de estudiar sus necesidades de capital externo con suma cautela.

- La necesidad de continuar estudiando y de ir creando mejores estándares intemacionales para fortalecer la estabilidad del sector financiero intemacional, de regular el comportamiento de los actores financieros del sector privado, perfeccionar los mecanismos jurídicos, mejorar el acceso y manejo de la información, condicionar el grado de participación en el sistema en función de las políticas económicas de los Estados participantes.

- La conveniencia de continuar replanteando el rol de las instituciones multilaterales, la intemacionalización de las finanzas y el fortalecimiento de las instituciones supra-nacionales, y el rol de las instituciones financieras privadas en el marco internacional.

Es de esperar que las lecciones de la reciente crisis sean tomadas en cuenta para llevar al plano supranacional prácticas y reglas que fomenten mayor estabilidad financiera entre y dentro de los Estados en un mundo todavía más complejo y dinámico. Tanto acreedores como deudores, al tomar las decisiones sobre financiamiento externo, deben recordar que el comportamiento histórico de las grandes instituciones financieras privadas está plagado de descalabros y ejemplos de irracionalidad. Como bien señala recientemente un destacado analista financiero sobre los "sofisticados" traders de los mercados de capitales, éstos "en ocasiones, son propensos a una avaricia insensata, a una complacencia pavorosa y a una cobardía pusilánime", suficientes como para obviar cualquier medida de racionalidad en el análisis de sus decisiones de negocios. 102 Valga la advertencia.

102 John Hussman, editor de Hussman Econometrics. Citado en artículo de J.R Laing, “. No random walker", Barron's, 7 de noviembre de 1994, p. 17. 


\section{Bibliografía}

AmericaEconomía, Número Especial: Las 500 empresas más grandes de América Latina, 1993-94.

AmericaEconomía, Nº92, febrero, 1995.

Aliber, Robert A.," "A Conceptual Approach to the Analysis of External Debt of Developing Countries", World Bank Staff Working Paper, N'421, octubre, 1980.

Armendáriz de Aghion, Beatriz, "An explanation of commercial bank lending behavior after 1982", Journal of International Economics, Vol. 28, No1/2, febrero, 1990.

Bacha, Edmary Díaz Alejandro, Carlos, "Los mercados financieros: una visión desde la semiperiferia", en: French-Davis, Ricardo (ed.), Relaciones Finañcieras Externas y Desarrollo Nacional. México: Fondo de Cultura Económica, 1983.

Benadava, Santiago, "Derecho Internacional Público", Mamuales Juridicos, No69, Tercera Edición Actualizada, Santiago Editorial Jurídica de Chile, 1989.

Bergsten, C. Fred, Cline William, y Williamson, John, Bank lending to developing countries: the policy alternatives. Washington, D.C.: Institute for International Economics, 1985.

Betancourt, Emesto y Dizard, Wilson III, Fidel Castro y la banca intemacional: cómo se hipoteçó una naçión en 20 años. Washington, D.C.: Fundación Nacional Cubano-Americana, 1982.

Bianchi, Andrés (comp.), La deuda externa latinoamericana. Buenos Aires: Grupo Editor Latinoamericano, 1985.

Biggs, Gonzalo, "Aspectos legales de la deuda pública latinoamericana: la relación con los bancos comerciales", Revista de la CEPAL, N²5, abril, 1985.

Biggs, Gonzalo, La crisis de la deuda latinoamericana frente a los precedentes históricos. Buenos Aires: Grupo Editor Latinoamericano, 1987.

Bitar, Sergio, La inversión extranjera en América Latina, p. 68.

Blessing, Werner, Punto de vista de la banca comercial. Londres: BID/,international Herald Tribune, 1986.

"Bottomless Debt", The Economist, 11 de diciembre de 1982.

Bouzas, Roberto, Entre la heterodoxia y el ajuste: negociaciones financieras externas de América Latina (1982-1987). Buenos Aires: Grupo Editor Latinoamericano, 1988.

Brownlie, Ian, Principles of public international law . Oxford: Clarendon Press, 1979, tercera edición. 
Carvounis, Chris, "Less developed countries' debt problem: trends in country risk analysis and rescheduling exercises", Columbia Journal of World Business, Primavera 1982.

Capitulos del SELA, :N¹9, abril-junio, 1988.

CEPALONU, "La evolución del problema de la deuda extema en América Latina y el Caribe", 30 de marzo de 1988.

Clark, Jobn, "Debt reduction and market reentry under the Brady Plan", FRBNY Quarterly Review, Inviemo 1993-94.

Clawson, Patrick, "Politics, not economics, key to debt patterns", The Wall Street Journal, 10 de abril de 1989.

Cline, William, "La deuda internacional: análisis, experiencia y perspectivas", Revista de la Planificación, No16, 1985.

Cline, William R, "The issue is illiquidity, not insolvency", Challenge, julioagosto, 1984.

Cline, William, "Statement before the Subcommittee on Foreign Operations and Related Programs for the Appropriations Committee", U.S. House of Representatives, Senior fellow, Institute for International Economics, 4 de marzo de 1987.

Cohen, Robert $\mathrm{E}$, "La crisis de la deuda y los préstamos bancarios a las filiales trasnacionales en América Latina", Economía de América Latina, №11, 1er. semestre, 1984.

"Consenso de Cartagena, Reunión de Ministros"; Comercio Exterior, abril, 1987.

Cooke, Stephanie, "Salvaging debt-equity swaps", Institutional Investor, septiembre, 1989.

Davis, Harold E, History of Latin America. New York: The Ronald Press Company, 1968.

Davis, Stephen " "The allure of ADRs", Institutional Investor, septiembre, 19:9.4.

Devlin, Robert, "Banca privada, deuda y capacidad negociadora de la periferia: teoría y práctica", en: Andrés Bianchi (ed.), op. cit.

Devlin, Robert, "Co-responsabilidad de la banca internacional en la crisis latinoamericana: hacia una formulación técnica", Capitulos del SELA, №15, enero-marzo, 1987.

Devlin, Robert, "Deuda extema y crisis: el ocaso de la gestión ortodoxa", Revista de la CEPAL, N²7, diciembre, 1985.

Devlin, Robert, "Evaluación de los critierios ortodoxos de la reprogramación de la deuda externa", Capitulos del SELA, No6, agosto, 1984.

Devlin, Robert, 'La deuda externa y el desarrollo económico: América Latina en la encrucijada", Colección Estudios de CIEPLAN, No 17, octubre, 1985.

Devlin, Robert, "La banca privada internacional y el endeudamiento de América Latina", Comercio Exterior, Vol. 33, N7, México, julio, 1983. 
Devlin, Robert, "Los bancos comerciales y el desarrollo de la periferia: congruencia y conflicto", Revista de la CEPAL, diciembre, 1979.

Devlin, Robert "Renegociación de la deuda latinoamericana: un análisis del poder monopólico de la banca", Revista de la CEPAL, N20, agosto, 1983.

Dinenzon, Marcelo y Hopenhayn, Benjamin, Liquidez internacional y deuda: un análisis de la generación y distribución de la liquidez internacional y su relación con el problema de la deuda. Buenos Aires: CISEA, 1988.

Dornbush, Rudiger, "La economía mundial: tópicos de interés para América Latina", en:Ffrench-Davis, Ricardo y Feinberg, Richard (eds.), Más allá de la crisis de la deuda: bases para un nuevo enfoque. Santiago: CIEPLAN, Diálogo Lationoamericano, 1987.

Dombush, Rudiger y Fisher, Stanley, "El problema mundial de la deuda: orígenes y perspectivas", Revista de la Planificación del Desarrollo, $\mathrm{N}^{\circ} 16,1985$.

División de Desartollo Económico de la CEPAL, "Políticas de ajuste y renegociación de la deuda externa en América Latina", Bianchi, Andrés (ed.), op. cit.

Edwards, Sebastián, "Deuda externa y desarrollo de pais", Cuadernos de Economía, Año 21, №62, abril, 1984.

"El comportamiento de los bancos trasnacionales y la crisis internacional de endeudamiento", Estudios e İnformes d̈e la CEPAL, №76, Santiago, 1989.

Eminger, Otmar, "The international debt crisis and the banks", Intereconomics, mayo-junio, 1985.

Estévez, Jaime, Inversión, ahorro y ajuste externöen América Latina. Washington, D.C.: Interamerican Develópment Bank, 1985.

Federal Reserve Bülletin, $(69,5)$, mayo, 1983.

Feinberg, Richard, "La deuda latinaomenicana: renegociando el costo del ajus-, te", en: Ffrench-Davis Ricardo y Feinberg, Richard (eds.), Más allá de la crisis de la deuda: bases para un nuevo enfoque, op. cit.

Félix, David, "Alternative outcomes of the Latin American debt crisis: lessons from the past", Latin American Research Review, Vol. XXI, N22, 1987.

Ffrench-Davis, Ricardo, "Deuda externa, ajuste y desarrollo en América Latina", en: Ffrench-Davis, Ricardo y Feinberg, Richard (eds.), Más allá de la crisis de la deuda: bàsës para un nüevó enfoque, op. cit.

Ffrench-Davis, Ricardo, "Deuda externa, industrialización y ahorro en América Latina", Colección Estudios de CIEPLAN, N¹7, 1985.

Ffrench-Davis, Ri'cardo, "Déuda externa y alternativas de desarrollo en América Latina", Apuntes CIEPLAN, No49, junio, 1984.

Ffrench-Davis, Ricardo, "Estrategias de los paises en desarrollo sobre la toma y el otorgamiento de préstamos privados internacionales", Journal of Development Planning, No14, 1984. 
Ffrench-Davis, Ricardo y Feinberg, Richard (eds.), Más allá de la crisis de la deuda. bases para un nuevo enfoque, op. cit.

Ffrench-Davis, Ricardo y Molina, Sergio, "Perspectivas del crédito bancario a los países en desarrollo en el resto del decenio de 1980", Revista de la Planificación del Desarrollo, $\mathrm{N}^{\circ} 16,1985$.

"Final Report to the Development Commission. Task Force on Non-Concessional Flows", IMF/World Bank, 15 de abril de 1982.

Folkerts-Landau, David, "The changing role of international bank lending in development finance", IMF Staff Papers, Vol. 32, N2, junio, 1985.

Forsyth, Randall W., "Just say no", Barrons, 7 de noviembre de 1994.

Furtado, Celso, La economía latinoamericana: formación histórica y problemas contemporáneos. México: Siglo Veintiuno Editores S.A., 1976.

Ganoe, Charles, "A banker's view of country analysis", Developing country debt.

Giersh, Herbert y Walter, Frank, "Towards an Explanation of the Productivity. Slowdown: An Acceleration- Deceleration Hypothesis", Economic Journal, 93, marzo, 1983, p. 36.

Golubff, Eva y Hopenhayn, Benjamin, "Fuga de capitales y deuda externa (algo para recordar)", El Bimestre Político y Económico, ler. bimestre 1989, №3.

González, Heliodoro, "Latin American debt crisis: the bailout of the banks", Inter-American Economic Affairs, Vol. 39, No3, Invierno 1985.

Griffith-Jones, Stephany, "¿De quién es la crisis de la đeuda?”, Cuadernos del CLAEH, Año 12, No43, 2a. serie, 1987-3.

Griffith-Jones, Stephany y Sunkel, Osvaldo, La crisis de la deuda y del desarrollo en América Latina: el fin de una ilusión. Buenos Aires: Grupo Editor Latinoamericano, 1987.

Griffith-Jones, Stephany, "Learning to live with crisis", The Banker, septiembre, 1987.

Griffith-Jones, Stephany, "The great escape", The Banker, septiembre, 1987.

Griffith-Jones, Stephany, "The growth of multinational banking, the euro-clrrency market and their effects on developing countries", The Journal of Development Studies, Vol. 16, N22, enero, 1980.

Guergil, Martine, "La crisis financiera internacional: diagnosis y prescripciones", en: Andrés Bianchi (comp.), La deuda externa latinoamericana, op. cit.

Gwyinn, S.C., "Adventures en the loan trade", Harpers, septiembre, 1983.

Heller, Robert y Frenkel, Emanuel, "Determinants of LDC Indebtedness", Journal of World Business, Vol. 17, No1, Primavera 1982.

Hillocoat, Guillermo y Quenan, Carlos, "La banca siempre gana: estrategia de los acreedores frente a la deuda externa" Nueva Sociead, No94, marzoabril, 1988. 
Horisaka, Kotaro, "Japanese banks and the Latin American debt problems", Revista de Economía Política, Vol. 10, No3 (39), julio-septiembre, 1990. Informe de la Reunión de Ministros, Consenso de Cartagena, Montevideo, 16. y 17 de diciembre de 1985, Comercio Exterior, abril, 1987. ., ;:

Ipsen, Erik, "The embattled debt negotiators", Institutional Investor, septiembre, 1989.

"La evolución del problema de la deuda externa en América Latina y el Caribe", Estudios de la CEPAL, 30 de marzo de 1988.

Kerry, John, "Congressional Record", U.S. Senate, 6 de noviembre de 1986.

Ketkar, Suhas y Natella, Stefano, "An introduction to emerging countries fixed-income instruments", CS FirstBoston, Emerging Countries Capital Markets, mayo, 1993.

Kuczynski, Pedro-Pablo, "Outlook for Latin American Debt", Foreign Affairs, Vol. 66, N¹, Otoño 1987.

Le Fort, Guillermo y Vial Ruiz-Tagle, Joaquín, “El problema del endeudamiento interno: aspectos analiticos", en: Massad, Carlos y Zahler, Roberto (eds.) Deuda Interna y Estabilidad Financiera, Volumen I: Aspectos analíticos. Buenos Aires: Grupo Editor Latinoamericano, 1987.

Lemoine, John E, "El incremento de los préstamos de los bancos comerciales a los países menos desarrollados no petroleros: algunos problemas analíticos", Monetaria, Vol. 3, No2, abril-junio 1980.

Laing, Jonathan R, 'No random walker", Barron's, 7 de noviembre de 1994. Maroni, Yyes, "Enfoque para evaluar el riesgo de los préstamos a países en desarrollo", Monetaria, Vol. 1, No1, enero-marzo, 1978.

Massad, Carlos, "El costo real de la deuda externa para el acreedor y para el deudor", Revista de la CEPAL, N¹9, abril, 1983.

Massad, Carlos, "La deuda externa y los problemas financieros de América Latina", Revista de la CEPAL, N20, agosto, 1983.

Massad, Carlos, "La deuda: un panorama general", Revista de la Planificación del Desarrollo, No16, 1985, p. 18.

Massad, Carlos y Zahler, Roberto, "El proceso de ajuste en los años ochenta", en: Bianchi, Andrés (ed.) La deuda externa latinoamericana, op. cit.

Meissner, Charles F., "Debt: reform without govemments", Foreign Policy, N'56, Otoño 1984: 81.

Michalet, Charles-Albert, "La crisis financiera internacional y el papel de los bancos multinacionales: una alternativa necesaria", Economía de América Latina, $\mathrm{N}^{\circ} 10$, primer semestre 1983: 15.

Mistry, Percy, "Third World debt: beyond the Baker Plan", The Banker, septiembre, 1987.

Mortimer, Michael, "Conductas de los bancos acreedores de América Latina", Revista de la CEPAL, No37, abril, 1989. 
Newman, Gray, "Como seducir al cápital fugado", AmericaEconomía, No 31 , septiembre, 1989.

Pastor, Manuel $\mathrm{Jr}_{\mathrm{r},}$ " :Gurrent aecount deficits and debt accumulation in Latin America: debate and evidence", Journal of Development Economics, Vol.31, No1, julio, 1989.

Pinto, Anibal, "Deuda extema y las responsabilidades compartidas", en: Rodríguez Céspedes, Ennio; Carrillo, C. y Mario, A. (eds.), Deudà externa: el caso de los países pequeños latinoamericanos. San José: EDUCA, 1987.

"Playing it close to the vest", Latin Finance, mayo, 1989.

Prebish, Raúl, ' $\mathrm{La}$ indisciplina monetaria internacional y el problema de la deuda", Revista de la Planificación del Desarrollo, N¹6, 1985.

Putnam, Bluford H. y Wilford, D.Sykes, The Monetary Approach to International Adjustment. New York: Praeger Publishers, 1978.

"Questions and Answers about U.S. Claims Against Cuba", Joint Committee on Cuban Claims, 1977.

Unal, Haluk, Demirguc-Kunt, Asli, y Leung, Kwok-Wai, "The Brady Plan, 1989 Debt Reductionv Agreement, and Bank Stock Returns in Untied States and Japan", Journal of Money, Credit and Banking, Vol. 25, №3, agosto, 1993, parte I.

Rhodes, William, Visión de los bancos comerciales con respecto a América Latina. Londres: BID/International Herald Tribune, 1986.

Ritter, A.M.R, "Cuba's convertible currency debt problem", CEPAL Re'view, No36, diciembre, 1986.

Robichek, Waiter, "El alivio de la deuda externa", Revista de la Planificación del Desarollo, No16, 1985.

Roett, Riordan, "Statement before the Subcommitte on International Development Institutions and Finance of the Committe on Banking, Finance and Urban Affairs", U.S. House of Representatives, 18 de marzo de 1986.

Ruíz Durán, Clemente, "América Latina: el problema de la deuda y propuestas de solución", Problemas del Desarollo, Vol. XVIII, N68, enero-marzo, 1987: 59.

Russel, Robert W., "Three windows on LDC debt: LDCs, the banks, and the United States national interest", en: Franco, Lawrence y Sieber, Marilyn, Developing Country Debt. New York: Pergamon Press, 1979.

Sachs, Jeffrey, "Recent Studies on the Latin American Debt Crisis"; Latin American Research Review, Vol.XXXI, No3, 1988.

Sachs, Jeffrey y Huinzinga, Harry, "U.S. commercial banks and the developingcountry debt crisis"; Brookings Papers on Economic Activity, 2:1987.

Sampson, Anthony, The money lenders: bankers and a world in turmoil. New York: The Viking Press; 1981.

Sánchez, Enrique P., "El servicio de la deuda en los países latinaomericanos en el decenio de 1980", Integración Latinoamericana, N94. 
SELA, "Situación de la deuda externa regional y convergencias para la negociación", apítulos del SELA, N220, julio-septiembre, 1988: 21.

"Separata resumen de clases del Profesor A. Rioseco para alumnos del curso de Organización Internacional Económica”, 2da. parte, Santiagé, Instituto de Estudios Intemacionales, Universidad de Chile, 1987.

Shapiro, Harvey D., "A modest uptick", Institutional Investor, septiembre, 1989.

Suter, Christian. "Long waves in the international financial system: cycles of sovereign borrowers", Review, XII, I, Invierno 1989.

"The Bond Book, Handbook of Emerging Market Bonds", Citicorp, ICFD Emerging Markets Research, 2da. edición, enero, 1994.

The Chase Manhattan Bank. "Credit Development Program Manuals" y otros documentos internos.

The Cuba Report, Vol. I, NoII, abril, 1993.

The impact of the Latin American debt crisis on the U.S.economy, U.S Congress, Joint Economic Committee, 1986.

Tomassini, Luciano, "El escenario internacional y la deuda externa de América Latina", Revista de la CEPAL, No24, diciembre, 1984: 137.

Ubok-Udom, Enamidem, "Development through debt: rationalizing the costs of external borrowing", Interconomics, Vol. 14, N4, julio-agosto, 1979.

Valdés, Salvador, "Origenes de la crisis de la deuda: $¿$ nos sobreendeudamos o nos prestaron en exceso?", Estudios Públicos, No33, verano 1989:135.

Vial, Joaquín y Le Fort, Guillermo, "Deuda externa y perspectivas de crecimiento en América Latina", Integración Latinoamericana, Año 109, $N^{0} 11$, enero-febrero, 1986: 19.

Weiner, Richard S., "International Finance: banks and bankruptcy", Foreign Policy, No50, Primavera 1983: 138.

Weiner, Richard S. y O'Cleireacain, Seamus, "Banca privada de EEUU y la deuda latinoamericana", Capítulos del SELA, No9, enero-junio, 1985:20.

Werlau, María, "Deuda extema e inversión extranjera como alternativas de ahorro externo en América Latina", Monografía, Programa de Magister, Instituto de Estudios Internacionales, Universidad de Chile, junio, 1988.

Werlau, María, "Es compatible el modelo neo-liberal con là realidad socio-cultural de América latina", Monografía, Programa de Magister, Instituto de Estudios Internacionales, Universidad de Chile, mayo, 1988.

White, Eduardo, La cuestión de las inversiones extranjerasy la crisis económcia en América Latina. Buenos Aires: Centro de Estudios de Desarrollo y Relaciones Intemacionales (CEDREI), 1986.

Zaidi, Iqbal Mehdi, "Saving, investment, fiscal defecits, and the external indebtness of developing countries", World Development, Vol. 13, N55, 1985. 